Review Article

\title{
A Review on the Structural Studies of Batteries and Host Materials by X-Ray Absorption Spectroscopy
}

\author{
Marco Giorgetti \\ Department of Industrial Chemistry “Toso Montanari," University of Bologna, Viale del Risorgimento 4, 40136 Bologna, Italy \\ Correspondence should be addressed to Marco Giorgetti; marco.giorgetti@unibo.it
}

Received 25 March 2013; Accepted 17 April 2013

Academic Editors: S. X. Dou, F. M. Labajos, Z. Luo, and Y. Masuda

Copyright (C) 2013 Marco Giorgetti. This is an open access article distributed under the Creative Commons Attribution License, which permits unrestricted use, distribution, and reproduction in any medium, provided the original work is properly cited.

\begin{abstract}
This review highlights the use of the X-ray absorption spectroscopy (XAS) as a local structural tool for selected atoms in several host materials. The main characteristics of XAS to be element-sensitive and its applicability to all states of matter, including crystalline solids and amorphous and liquid states, permit an in-depth study of the structural properties of a large variety of materials. This includes intercalation materials where a host structure can accommodate guest species. Host guest equilibria are at the basis of a large variety of technological applications; in particular they have been used for energy storage, ion-exchange membranes, electrochromism, and analytical sensing. A selection of XAS experiments conducted in the field of batteries, mainly on cathodes, and applications in the field of metal hexacyanoferrates and double layered hydroxides are outlined.
\end{abstract}

\section{Introduction}

Since the discovery of X-rays by Rontgen [1] over 100 years ago in his laboratory in Wurzburg, X-rays have provided a nondestructive testing of a wide variety of materials. Xray methods cover many techniques based on scattering, emission, and absorption properties of the X-ray radiation. $\mathrm{X}$-ray diffraction probes the order of matter at the atomic level and X-ray crystallography is essential in relating the atomic structure of solids to their functions and physical properties. A review on high energy X-ray diffraction from glasses and liquids has been published in this journal [2] recently. Xray emission spectroscopy makes possible the determination of the chemical composition of samples by simply looking at the emitted X-ray fluorescent lines and nowadays is one of the most useful analytical techniques [3]. The absorption property of X-rays has been used in analytical techniques based on contrast, like imaging and tomography. Owing to today's X-ray sources by which X-rays are generated by relativistic electrons or positrons in international laboratories, in storage rings machines, the beam intensity is trillions of times more brilliant with respect to traditional X-ray sources, offering unprecedented advantages. It is therefore possible to verify the existence of fine structures in X-ray absorption spectra and, once a theory has been formulated $[4,5]$, the $\mathrm{X}$ ray absorption fine structure (XAFS) (XAFS is another term used nowadays. The general preference is to use either XAS or XAFS to refer to the entire spectrum, which comprises the XANES (near the edge spectrum, within $30 \mathrm{eV}$ or so), and EXAFS to refer to the extended part. Therefore XAS = $\mathrm{XAFS}=\mathrm{XANES}+\mathrm{EXAFS}$ ) became a strong analytical tool for structural studies. Because XAFS does not require longrange crystalline order, it has been used with great success in many research fields, and the basic principles and several applications of the XAS spectroscopy have been illustrated in several books in the 80s $[6,7]$ and also recently $[8,9]$. Several reviews are also available, concerning development of the EXAFS theory [10], the application to liquids [11], catalysis $[12,13]$, and electrochemical interfaces [14]. A theme issue of the Journal of Synchrotron Radiation has been dedicated to BioXAS (biological XAS) [15] and another one appeared on the Coordination Chemical Reviews [16] on inorganic materials. An excellent explanation of the physics of the Xray and its interaction with matter is available in the book by Als-Nielsen and McMorrow [17].

An X-ray absorption spectrum is an accurate measure of the X-ray absorption coefficient as a function of incident $\mathrm{X}$-rays, in an energy range, that is, below and above the 


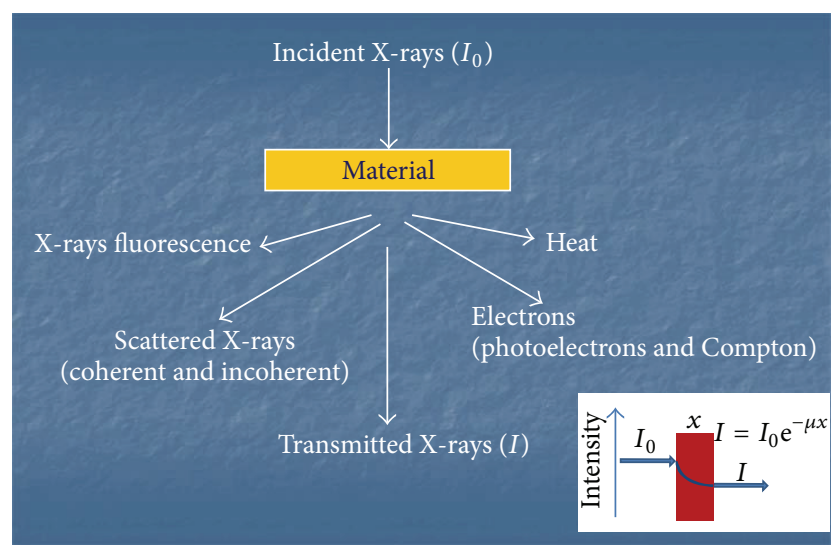

FIgURE 1: Interaction of X-ray photons with matter.

absorption edge of the selected element of material under investigation. Thus, it is element-specific and comprises electron transition and features that are modified by electron scattering with nearest neighbor atoms. An X-ray absorption spectrum can be divided into two regions which originate with different physical-chemical mechanism: XANES (X-ray absorption near edge structure) and EXAFS (extended X-ray absorption fine structure), even though the two structures can be recorded simultaneously in one X-ray absorption spectrum. The XANES region, comprising the absorption edge itself and the features immediately beyond the edge (to $\sim 100 \mathrm{eV}$ after the edge), is strongly sensitive to oxidation state and coordination chemistry of the absorbing atom of interest. The EXAFS region has been largely exploited to gain quantitative structural information such as first shell distance of the metal site and coordination number. EXAFS comprises periodic undulations in the absorption spectrum that decay in intensity as the incident energy increases well over $(\sim 1000 \mathrm{eV})$ the absorption edge. These undulations arise from the scattering of the emitted photoelectron with the surrounding atoms.

\section{X-Ray Absorption Coefficient and XAS}

When a sample is exposed to X-rays it will absorb part of the incoming photon beams, as indicated in Figure 1. This absorption is mainly generated by the photoelectric effect, especially for hard X-rays. Other phenomena occurring are heat, X-ray fluorescence and production of electrons (the detection of which is at the basis of an X-ray photoelectron spectroscopy experiment, XPS), and of course the scattering of X-rays which is another fundamental X-ray-material interaction. This scattering could be either coherent, also called elastic (i.e., X-ray diffraction, where the scattered photons interfere with each other) or incoherent, leading to the family of inelastic scattering-based techniques.

As displayed at the bottom of Figure 1, the absorption of $\mathrm{X}$-rays can be measured quantitatively, and it follows a similar exponential decay given by the Beer law (recent studies on the history of the Beer's law to the optical spectroscopy have indicated the Bouguer-Lambert-Beer law to be the more

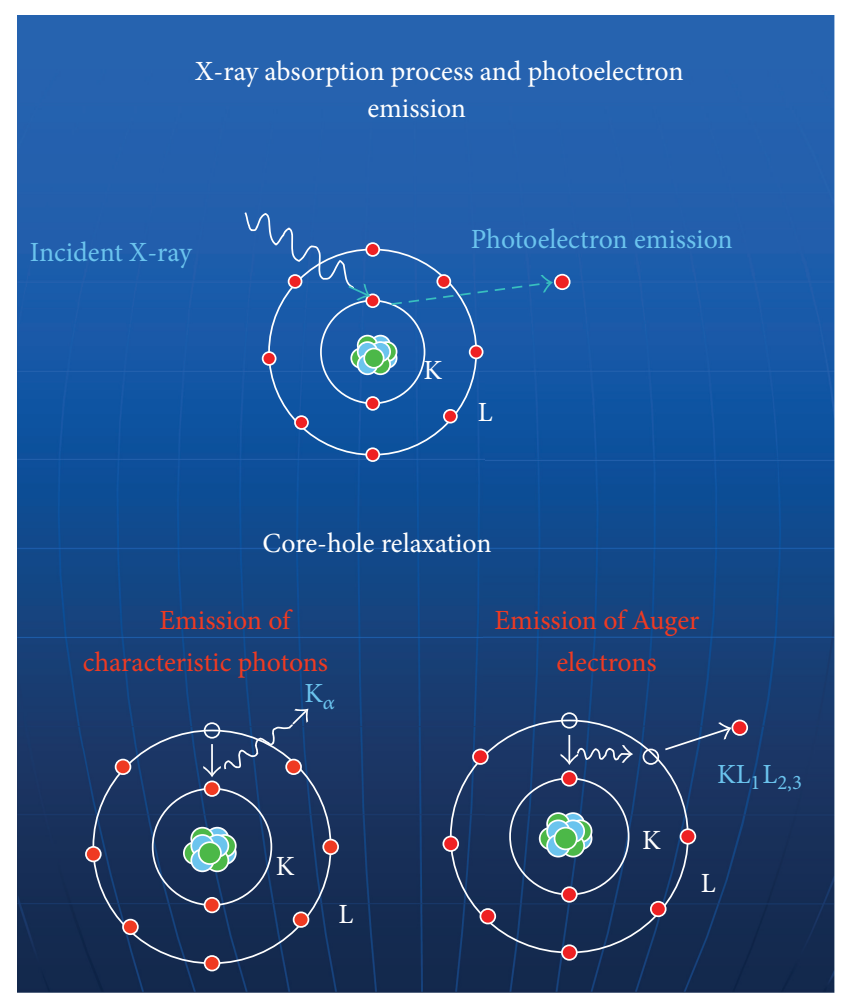

FIgURE 2: The photoelectric absorption process which creates core hole and its relaxation by fluorescent X-ray emission or Auger electron emission.

appropriate term to name this famous exponential decays) valid for optical transitions. The quantity of interest here is called linear absorption coefficient $\mu$ and it can be considered analogous to the absorbance $\varepsilon$ in UV-vis spectroscopy. It is measured in $\left[\mathrm{cm}^{-1}\right]$. Actually, because of the applicability to all states of matter, it is more convenient to use the mass absorption coefficient $\mu_{m}$ obtained by normalisation to the density of the material $\rho$, that is, $(\mu / \rho)$; therefore the dimension becomes $\left[\mathrm{cm}^{2} / \mathrm{g}\right]$. The absorption coefficient $\mu(E)$ describes how X-rays are absorbed as a function of energy E. Generally matter becomes more transparent to X-rays at higher energies; that is, $\mathrm{X}$-rays are more penetrating following a decreasing function proportional to $\left(1 / E^{3}\right)$ of the quantity $\mu(E)$. However, at a certain energy a dramatic increase of the absorption coefficient $\mu(E)$ can be observed, which is called $\mathrm{X}$-ray absorption edge, and this behavior is brought up by the photoelectric effect.

The X-ray photoelectric process which gives rise to such an absorption is summarised in Figure 2. An X-ray photon is absorbed by an atom, and the excess energy is transferred to an electron which is expelled from the atom, leaving it ionized. That electron is called photoelectron, and we will see how it is responsible for EXAFS mechanism. The electron vacancy created in the photoabsorption process leaves the atom in a very unstable condition and therefore two competing processes may occur. The first is X-ray fluorescence, in which a higher energy core-level electron fills the deeper core hole, ejecting an X-ray of well-defined energy providing 


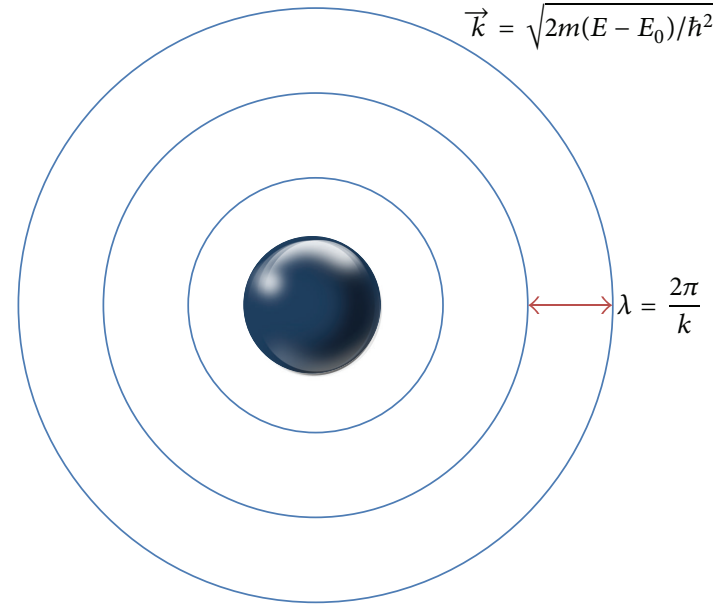

(a)

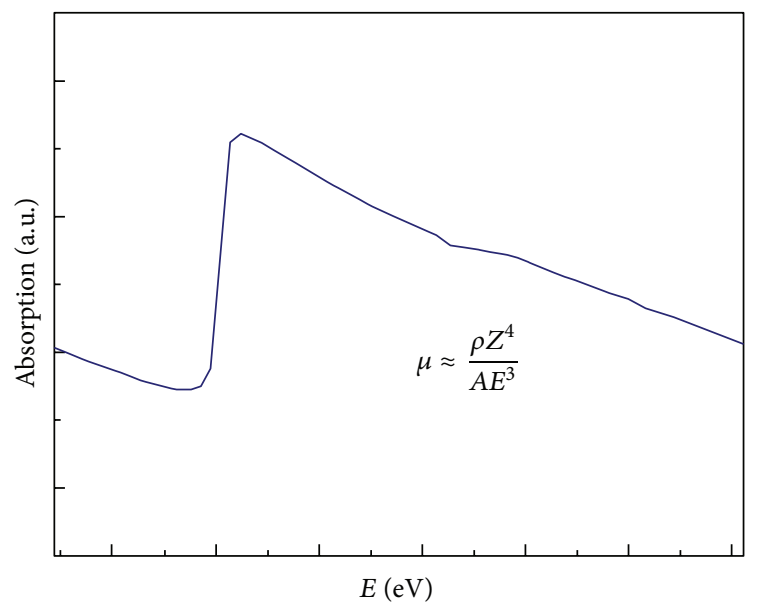

(c)

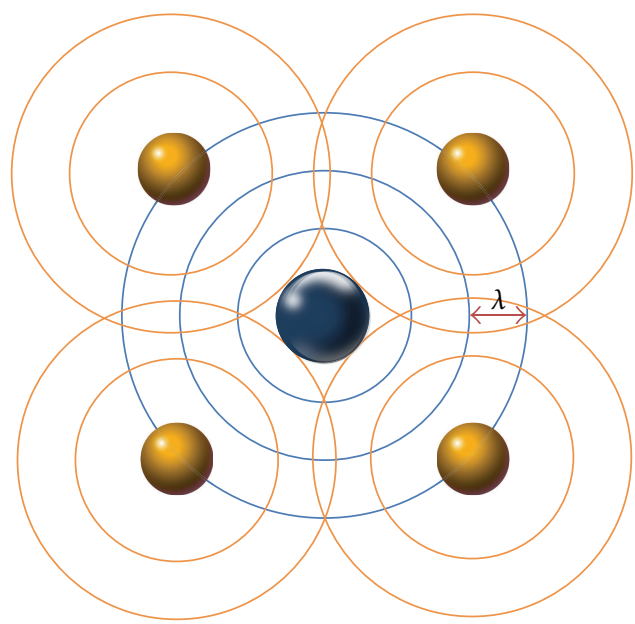

(b)

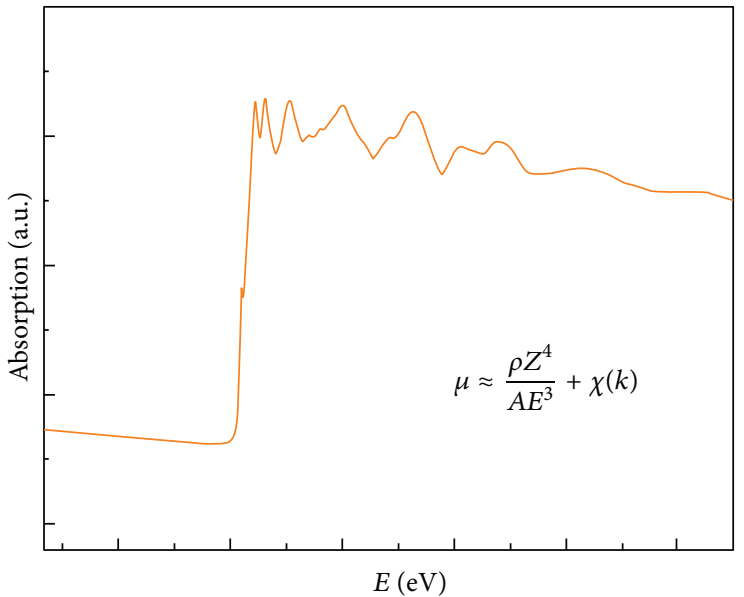

(d)

Figure 3: Emission of a photoelectron for an isolated ((a) and (c)) and a coordinated ((b) and (d)) atom. In the latter the absorption coefficient measured at a central atom threshold shows a fine structure due to the presence of neighboring atoms.

a unique signature of the atoms constituting the material once those photons are collected by a detector, as in X-ray fluorescence spectroscopy (XFS). The second process (for deexcitation of the core hole) is the Auger effect, in which an electron drops from a higher electron level and a second electron is emitted into the continuum. The measurement of these electrons is made possible by Auger spectrometers. In the hard X-ray region $(>2 \mathrm{keV}), \mathrm{X}$-ray fluorescence is more likely to occur than Auger emission, but for lower energy the Auger process dominates.

The EXAFS phenomenon arises from the quantummechanical interference resulting from the scattering of a photoelectron by the potential of the surrounding atoms. This is seen from Figure 3 where the photoelectron emitted by the photoabsorbing atom (blue) propagates as a spherical wave and spread out over the solid. At this point the mechanism can be different in case of an isolated atom ((a) and (c)) or a coordinated atom ((b) and (d)). In the latter case, the emitted photoelectron is reflected off by the neighbouring atoms (yellow) to the absorbing atom and so does every atom in the material. The amplitude of all the reflected electron waves adds either constructively or destructively to the spectrum of the absorbing atom and hence the X-ray absorption coefficient exhibits the typical oscillation depicted at the bottom right of Figure 3. A crucial issue is the recognition that the photoelectron is not infinitely long lived but must decay as a function of time and distance, and thus the EXAFS cannot probe long-range distances. EXAFS can give only local structural information, of about several angstroms around the selected atomic species. Of course, this mechanism does not happen in the case of isolated atoms like Ar gas, and therefore the corresponding X-ray absorption edge appears featureless as observed in Figure 3(c). From the time frame of the EXAFS phenomenon it is helpful to underline that this takes place at a time scale much shorter than that of atomic motion (also vibrations), so the measurement is a sum of instantaneous (snapshot) spectra of molecules at different stages of their vibrational cycle. This results in a damping of the EXAFS oscillations and is normally considered in the data analysis by means of an EXAFS Debye Waller like factor. Also EXAFS 


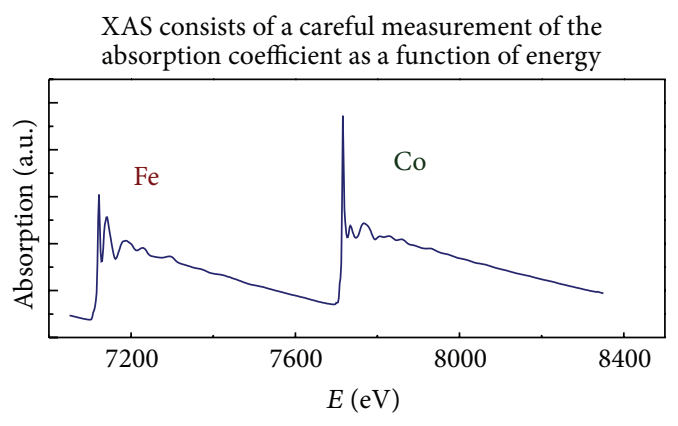

The EXAFS signal $\chi(k)$ is identified by the typical oscillations of absorption coefficient and carries structural information
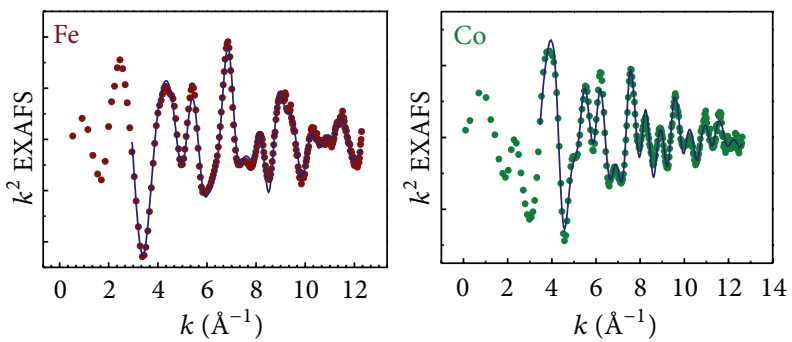

The fourier transform (FT) of $\chi(k)$ reveals the contribution from single atomic shells
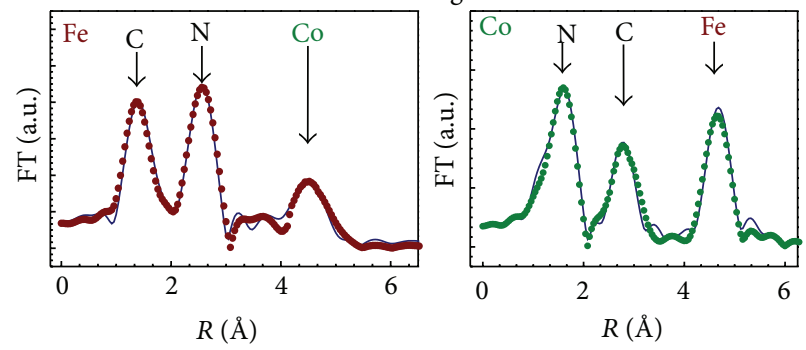

FIGURE 4: Summary of the EXAFS data recording and primary data reduction of a cobalt hexacyanoferrate sample. Due to the presence of $\mathrm{Fe}$ and $\mathrm{Co}$ in the sample, a simultaneous edge is observed. The oscillations of absorption coefficient carry structural information, and the FT operator gives the contribution arising from single atomic shells around the photoabsorber.

should be considered as a bulk technique, because all the materials which are actually under investigation contribute to the overall shape of the XAS spectrum. Figure 4 displays an example of EXAFS data recording and the successive data interpretation, including the extraction of the typical oscillations of the absorption coefficient and the Fourier transformation.

The XANES region contains a wealth of information. This region is not only sensitive to the geometrical structure within several angstroms around the central atom (photoabsorber) but also to its effective charge. The use of edge energy (which is commonly considered the energy of the inflection point on the spectrum of the 1st derivative curve) has proven to be very useful in the determination of the oxidation state of the photoabsorber. This can be simply explained considering that atom with a higher oxidation state should have a higher charge, thus requiring more energy for the ejection of a core electron. Another useful portion of the XAS spectrum is the preedge. It is well known that preedge structures [18] are observed in the rising part of the K-edge spectra of first raw transition metal. The occurrence of this peak is due to $1 \mathrm{~s}-3 \mathrm{~d}$ electronic transition, that is, electric dipole forbidden but quadrupole allowed. It is generally seen that complexes in noncentrosymmetric environment have more intense pre-edge features than centrosymmetric complexes, and therefore these peaks can be used as a probe for geometry. The intensity increases following this criterion for geometry: octahedral < square-pyramidal $<$ tetrahedral. The increase in intensity has been attributed to metal $4 \mathrm{p}$ mixing into $3 \mathrm{~d}$ orbitals which provides some electric dipole allowing $1 s-4 p$ character to the transition, and this mixing is favored by geometrical distortion of the core site. To date, a study has reported [19] on the Fe K-edge multiplet analysis of the 1s$3 \mathrm{~d}$ component, and the same has been done for several other metals $[20,21]$. The electric dipole or quadrupole nature of the transition has been studied [22, 23]. It is worth pointing out that pre-edge features have been strongly used in studies concerning cathode materials based on transition metals oxide, like $\mathrm{V}_{2} \mathrm{O}_{5}$, in order to deduct some relevant chemical information.

\section{Experimental and In situ Studies}

A typical XAS experiment is conducted using synchrotron radiation because the high intensity source guarantees high $\mathrm{S} / \mathrm{N}$ of the measurement. This allows catching any oscillatory structure of the absorption coefficient, that is, the structural content of an X-ray absorption spectrum. The experimental setup of an XAS beamline is described in several books $[6,8]$ hence it will not be specified here. Basically, two geometries are used for this purpose, namely, transmission and fluorescence, even though electron yield detection of XAS can be possible and it is particularly important for studies of surfaces.

In transmission geometry the sample is placed between Io and I detectors and the absorption is measured according to the Beer law exponential decay, as mentioned before. The fluorescence detection is carried out by tilting the sample of 45 degrees and collecting the fluorescence $\mathrm{X}$-rays by using a solid state detector at the right angle with respect to Io. One of the advantages of XAS spectroscopy in the field of battery materials is the use of in situ recording, that is, to collect XAS spectra during a discharge or charge process. To perform such an experiment, a spectroelectrochemical cell needs to be designed. The experimental aspects of which have been reviewed and explained in several articles [14, 24]. This cell consists of a cathode, which contains the active material, a lithium foil, a separator, which is typically a polymeric membrane like Celgard, an electrolyte, and a solvent, typically polypropylene carbonate (PC) or ethylene carbonate (EC). The cell is packaged in a dry-box, sealed and adapted to the beamline, as shown in Figure 5. The term operando has also been used in the community which indicates more generally the recording of an XAS spectrum under reaction conditions. Therefore it is often used in the field of heterogeneous catalysis in order to assess the molecular structure of the active phase [10, 11]. 

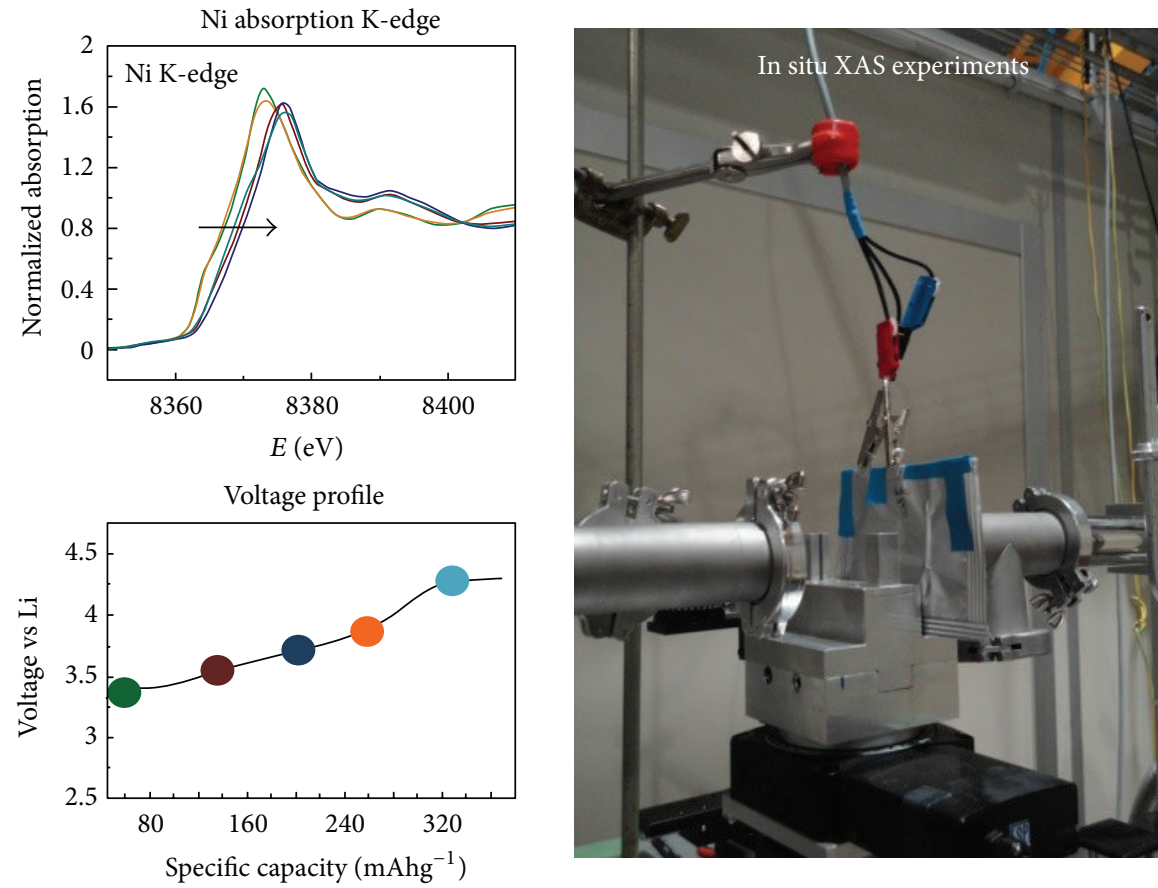

Figure 5: Typical experimental set-up for an in situ XAS experiment on a battery. The experiment has been conducted at ELETTRA synchrotron radiation in Basovizza, Italy. A selection of XANES spectra at the Ni K-edge taken during the experiments is displayed and corresponds to a selected state of charge of the voltage profile, defined by the same color of the lines.

Figure 5 also displays the common strategy of analysis of these in situ experiments. XANES and EXAFS spectra are collected at a specific state of charge (or discharge) of the battery, which are indicated by the same color in the figure. In this way, all the structural and electronic modifications occurring at the selected site upon lithium insertion and release are highlighted and can be successively studied. The example in Figure 5 deals with a cathode material based on nickel oxide. Certainly, in case of cathode with several metal in the structure, like the new lithium-excess manganese layered oxide, which is a solid solution of $\mathrm{Li}_{2} \mathrm{MnO}_{3}$ and $\mathrm{LiCo}_{1 / 3} \mathrm{Ni}_{1 / 3} \mathrm{Mn}_{1 / 3} \mathrm{O}_{2}$, the XAS can be tuned to all metal sites to reveal both structural and charge modifications of each metal core.

\section{Data Analysis}

Data analysis of an XAS spectrum is generally done using code programs which can perform ab initio calculations, and they are useful for either XANES or EXAFS. Once a spectrum has been registered during dedicated beam time at synchrotrons, the easiest way to see the spectra and to perform a general data manipulation is using the IFEFFIT program [25]. Computer code programs which simulate the XANES spectrum are MXAN [26] and FDMNES [27]. MXAN is also able to fit the XANES part (from the edge to about $200 \mathrm{eV}$ ) of experimental X-ray absorption data. The method is based on the fitting between the experimental spectrum and several theoretical calculations generated by changing the relevant geometrical parameters of the site around the absorbing atom. The X-ray photoabsorption cross-section is calculated using the full multiple scattering scheme. A computer program which is used for the analysis of metal L-edge and EELS (electron energy loss spectroscopy) is called CTM4XAS and it is also available [28].

For the EXAFS analysis there are basically three computer programs: GNXAS [29, 30], FEFF [31, 32], and EXCURVE $[33,34]$. Briefly, the GNXAS package is an advanced software for EXAFS data analysis based on multiple-scattering (MS) calculations and a rigorous fitting procedure of the raw experimental data, which allows to fit simultaneously any number of spectra containing any number of edges, to use directly the raw data without any preanalysis, to account for complex background multielectron excitation features, to use various model peaks for the doublet, triplet, and quadruplet distribution functions, including non-Gaussian distribution models. FEFF is an automated program for $a b$ initio multiple scattering calculations of X-ray absorption fine structure (XAFS) and X-ray Absorption Near-Edge Structure (XANES) spectra for clusters of atoms. The code yields scattering amplitudes and phases used in many modern XAFS analysis codes. The last version of the code, FEFF9, has been released and its features were summarized recently by Rehr [35]. EXCURV is a program which simulates EXAFS spectra using rapid curved wave theory from the parameters of the radial shells of atoms surrounding the central atom. Figure 6 shows a detailed example of EXAFS data analysis, in terms of single atomic contribution, which is due to the various atoms surrounding the photoabsorber. The figure also displays the relative FT of the EXAFS signal. 

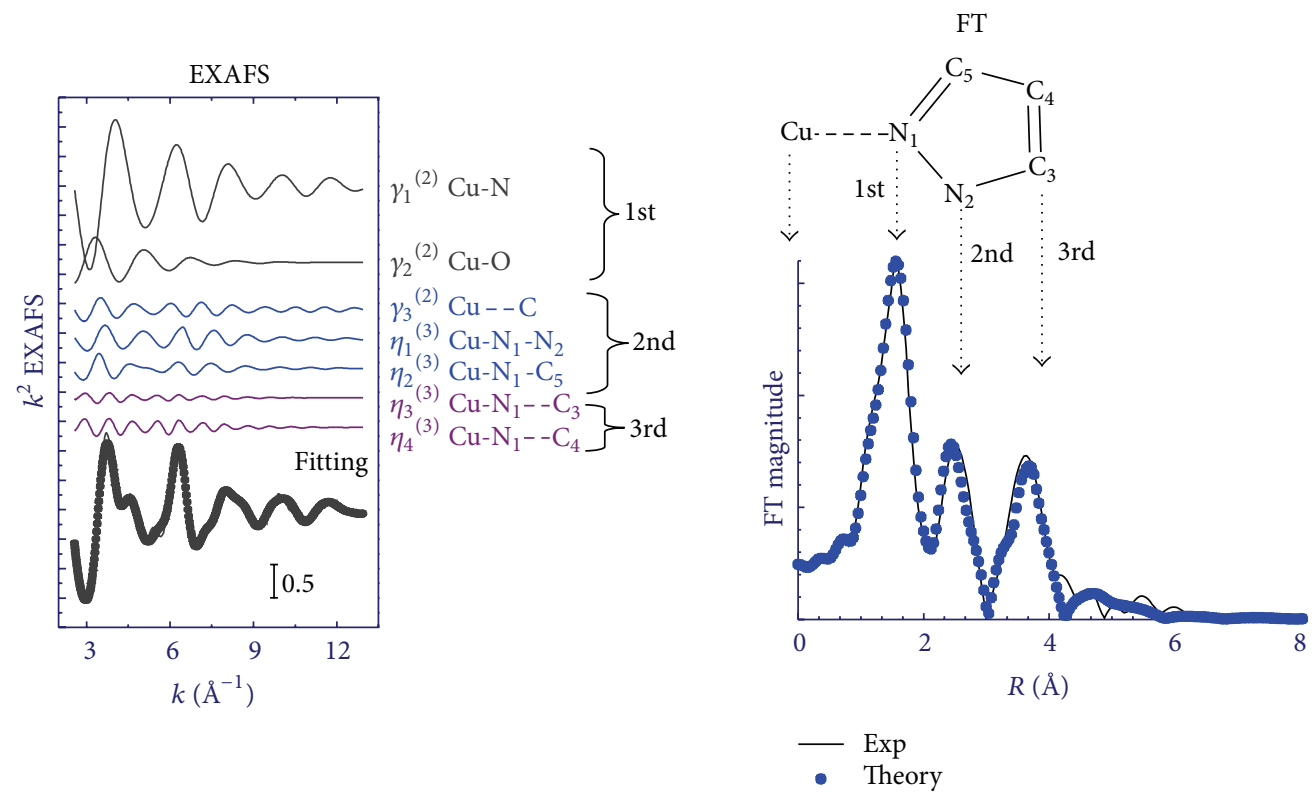

FIgURE 6: Example of detailed EXAFS data analysis using the GNXAS set of programs. The EXAFS panel displays the various single contribution to the total theoretical signals and their comparison to the experimental one at the bottom. Signals are mainly grouped in 3 shells. The FT panel displays the theoretical and experimental FTs compared. The three main peaks are related to the atomic species belonging to the near imidazole, as indicated by arrows in the figure, and correspond to the three grouped shells of the EXAFS panel.

A typical consequence of an in situ XAS experiment, where the absorption coefficient is measured during a change of an external variable, is the large number of XAS data files produced. This is particularly true in the case of a spectroelectrochemical experiment involving a battery during the charge/discharge process. Recently, a methodology based on a joint chemometry, dynamic XAS approach, has been proposed, allowing a more complete understanding of the cell dynamic during charge/discharge processes [36]. Briefly, by applying the multivariate curve resolution (MCR) analysis [37] to a complete set of XAS spectra (about 60) obtained on a $\mathrm{Cu}_{0.1} \mathrm{~V}_{2} \mathrm{O}_{5}$ xerogel cathode during the charge, it was possible to determine the number of species involved in the experiment and the range of existence of each of them and to obtain the spectra of the pure components. For the viewpoint of the cell dynamic, this data treatment evidenced the occurrence, for the first time, of three species during the battery charging. The structural identification has been revealed by the successive EXAFS analysis, which has confirmed three different chemical environments of $\mathrm{Cu}$ during the experiment (for a more complete list see the ESRF website at http://www .esrf.eu/Instrumentation/software/data-analysis/Links/xafs).

\section{Applications to Battery Materials}

There is a tremendous interest in batteries with high energy and high power density for a wide variety of applications, from portable equipment, computer laptops, to hybrid electric vehicles and also batteries for load levelling [38-40]. In this context, fundamental studies of high rate intercalation into nanostructured and microstructured porous hosts have been performed in order to explore the insertion properties of guest ions such as lithium or sodium, into the host structure, which identifies the cathode in a battery. The rate and efficiency of such intercalation reactions are of fundamental importance to the chemists because they permit the use of the hosts in intercalation batteries [41]. In this context, Liinsertion compounds (and hence Li-battery technology) have been the subject of intensive research based on the fact that $\mathrm{Li}$ is the most electropositive $(-3.04 \mathrm{~V}$ versus SHE, standard hydrogen electrode) as well as the lightest (equivalent weight $6.93 \mathrm{~g} / \mathrm{mol}$ ) metal, thus facilitating the design of storage system with high energy density [41].

Among the most known Li-insertion compounds used for cathode materials, $\mathrm{V}_{2} \mathrm{O}_{5}$-based structure, $\mathrm{Li}_{(x)} \mathrm{CoO}_{2}$, or $\mathrm{LiNiO}_{2}$ or $\mathrm{LiNi}_{(1-x)} \mathrm{Co}_{(x)} \mathrm{O}_{2}$ layered rock salt system as well as manganese spinel system, $\mathrm{Li}_{(x)} \mathrm{Mn}_{2} \mathrm{O}_{4}$, have been extensively studied and used in commercially rechargeable batteries [41, 42]. Some of them have intrinsically crystalline structure, but composite electrodes based on porous gel materials, have frequently been proposed. For instance, aerogels and similar nanostructured porous hosts are among these new materials that promise to enhance the rates of intercalation without those compromising their excellent thermodynamic characteristics [43]. New studied materials also include lithium iron phosphate, $\mathrm{LiFePO}_{4}$, in both amorphous and crystalline states, which present the advantage of using $\mathrm{Fe}$ which is inexpensive and nontoxic. Iron is also considered the fourth most abundant element in the Earth's crust. Figure 7 is a sketch of the amorphous $\mathrm{V}_{2} \mathrm{O}_{5}$ gel structure. The typical layered structure is observed, with only difference in interplanar distance among layers. The displayed layered structure also holds true for $\mathrm{Li}_{(x)} \mathrm{CoO}_{2}$ and $\mathrm{Li}_{(x)} \mathrm{NiO}_{2}$. In those layered materials the space among layers can be used 


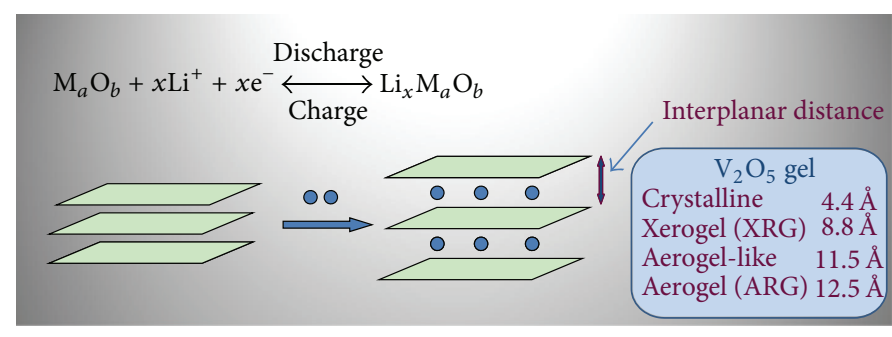

FIGURE 7: Sketch of the layered metal oxide samples used as cathode materials in lithium rechargeable batteries. The large void space between the planes (layers) serves as a channel for the lithium insertion and release process. The distance between planes depends on the preparation conditions, in gel-based $\mathrm{V}_{2} \mathrm{O}_{5}$.

to accommodate lithium in reversible intercalation/release reactions, and the layered structure is normally retained during the process.

Because of the amorphous, ill-crystalline state led by these materials after intercalation/release processes, X-ray absorption spectroscopy (XAS) is the technique of choice for retrieving structural and electronic information. The main characteristics of these studies include the following: (i) XAS is an element-specific technique which allows to select a particular metal threshold (generally a K-edge) to obtain the local structure around a selected metal atom; (ii) XAS could be tuned to different sites (e.g., Fe and P in amorphous $\mathrm{LiFePO}_{4}$ ) giving two independent absorption signals even if we are investigating the same compound, enhancing therefore the reliability of the analysis; (iii) X-ray absorption near-edge spectroscopy (XANES) can be used to reveal the formal oxidation state of the probed atom as well as information concerning the symmetry of the metal site; (iv) XAS is a local probe and therefore can be complemented with XRD measurements (in case of crystalline materials) for long range order studies; (v) the possibility of doing in situ measurements where the XAS spectra are collected during charge and discharge. In this case the structural modification of the metal site can be monitored during the electrochemical process while the XANES portion of the spectrum provides quantitative information about the change of oxidation state and local symmetry.

In general, the characterization of the local structures of intercalation hosts by XAS is intended to reveal the nature of the sites for intercalation, the changes of these structural sites during insertion/release of lithium, and the reversibility of structural changes during cycling with in situ techniques. The use of EXAFS spectroscopy in the field of battery materials has been first reported by Mc Breen in a pioneering work [44], and reviewed successively [45-47], and also recently reported by other authors $[48,49]$. This section summarises a selection of studies of the most promising candidates for positive electrode materials for lithium batteries [41, 42] conducted by XAS techniques: $\mathrm{V}_{2} \mathrm{O}_{5}$-based structures [50], $\mathrm{LiCoO}_{2}$ layered structure, $\mathrm{LiMn}_{2} \mathrm{O}_{4}$-based spinel structure, and the $\mathrm{LiFePO}_{4}$ olivine structure. Historically, the first studies dealt with the vanadium pentoxide gels; therefore we will highlight them first. A comprehensive account of the XANES characteristics of a series of vanadium oxides has been reported by Wong et al. [51].
5.1. Vanadium Oxide-Based Materials. The first studies of $\mathrm{V}_{2} \mathrm{O}_{5}$ material for lithium batteries have been conducted in the early 90s, with experimental works done at the Synchrotron LURE in France [52] using an in situ cell [53]. Followed research is conducted at the University of Camerino on $\mathrm{LiV}_{3} \mathrm{O}_{8}$ [54] and $\mathrm{NaV}_{3} \mathrm{O}_{8}$ [55], using the same beamline. Crystalline $\mathrm{V}_{2} \mathrm{O}_{5}$ [56] and vanadium doped manganese gel [57] have also been reported. Successively, an extensive use of the XAS spectroscopy on materials based on sol-gel synthesis of vanadium oxides, has been done mainly by researchers at the University of Minnesota, conducting experiments at LURE, France, and Brookhaven National Laboratory, USA. Those materials are generally amorphous and have intercalation capacity as high as $650 \mathrm{Ah} / \mathrm{kg}$ with corresponding specific energies exceeding $1600 \mathrm{Wh} / \mathrm{kg}$. The local structural modification of $\mathrm{V}_{2} \mathrm{O}_{5}$ aerogel materials has been investigated in a series of chemically intercalated samples [58]. An in situ XAS study conducted on $\mathrm{V}_{2} \mathrm{O}_{5}$ xerogel upon lithium intercalation and release [59] revealed the changes of the effective charge of vanadium. For the first time, the structural reversibility of $\mathrm{V}_{2} \mathrm{O}_{5}$ xerogel which extends up to $5 \AA$ around the vanadium site has also been proven. Successively, similar studies by in situ XAS have been conducted on the aerogel and ambigel vanadium oxide cathodes [60, 61] and on $\mathrm{LiNiVO}_{4}$ material [62]. The structure of the pristine $\mathrm{V}_{2} \mathrm{O}_{5}$ xerogel has been studied by EXAFS spectroscopy in a grazing incidence geometry [63] analysing the local environment of the vanadium site along the $z$-direction, further proving the occurrence of a bilayer structure due to two sheets of $\mathrm{V}_{2} \mathrm{O}_{5}$ facing each other. The EXAFS fitting has confirmed the existence of a vanadium-vanadium interaction between two different $\mathrm{V}_{2} \mathrm{O}_{5}$ layers and an oxygen bridge between them. The large asymmetry of $\mathrm{VO}_{6}$ units in vanadium oxide materials makes the EXAFS analysis of the first shell a challenging one, and the use of intrinsically polarized synchrotron radiation $\mathrm{X}$-ray beam was necessary to discriminate contribution from $x-y$ plane to the $z$-axis in an oriented sample. A combined analysis of $x-y$ and $z$-axis polarized EXAFS spectra has permitted to build up the most suitable fitting parameters for an EXAFS spectrum recorded on the powder of $\mathrm{V}_{2} \mathrm{O}_{5}$ aerogel, demonstrating consistency of the polarized and the powder experiment [64].

To enhance the rate of insertion, amorphous $\mathrm{V}_{2} \mathrm{O}_{5}$ was doped with several polyvalent cations such $\mathrm{Ag}, \mathrm{Cu}$, and $\mathrm{Zn}$. An increase of the conductivity by more than three orders of 
magnitude was observed. Subsequent intercalation of $\mathrm{Li}^{+}$into the doped materials proved to be facile and highly reversible. To study the structural sites of the polyvalent ions, XAS spectra have been recorded at the zinc, copper and vanadium $\mathrm{K}$-edges in a series of aerogel-like and xerogel $\mathrm{V}_{2} \mathrm{O}_{5}$ doped materials $[65,66]$. X-ray absorption spectroscopy has been used to probe the local structure of vanadium pentoxide as well as the local environment of the inserted metal site, thanks to the selectivity of the EXAFS probe. A study on the $\mathrm{Zn}$ doped $\mathrm{V}_{2} \mathrm{O}_{5}$ samples permitted to identify an unconventional site for the guest metal, with the $\mathrm{Zn}$ ion interacting with a single bilayer [67]. Furthermore, a series of $\mathrm{Zn}$ and $\mathrm{Cu}$ doped aerogel-like $\mathrm{V}_{2} \mathrm{O}_{5}$ samples was investigated in a framework of collaboration between the University of Minnesota and the University of Bologna, demonstrating the equivalency of the preferred site for $\mathrm{Cu}$ and $\mathrm{Zn}$. The EXAFS analysis showed also that the vanadium atomic environment is not altered by the doping metal insertion and that copper and zinc are 4fold coordinated by almost coplanar oxygens in both xerogel and aerogel-like oxide hosts [68]. When the doping ions interact with a single bilayer, an important consequence is that the interlayer space is free and available for further ion insertion. This has been proved by an in situ XAS experiment on a $\mathrm{Cu}_{0.1} \mathrm{~V}_{2} \mathrm{O}_{5}$ xerogel cathode [69], a material that can deliver $180 \mathrm{mAh} / \mathrm{g}$ in 80 minutes and discharge for more than 450 cycles without any capacity fading. These excellent properties have been reported to be related to the "free" space. In addition, EXAFS data showed that the copper ion was reduced to metallic state during the lithium insertion and was reoxidised returning to the same site in the lattice upon lithium release. A further paper which highlights the ability of XAS technique to determine the preferred site of $\mathrm{Cu}$ and $\mathrm{Zn}$ as doping metal, in both aerogel-like and xerogel forms, using a straightforward application of multiple scattering (MS) formalism in the XAS data analysis, has been published by Giorgetti et al. [70]. In addition, samples of $\mathrm{LixV}_{3} \mathrm{O}_{8}$ have been the subject of soft X-ray absorption study as well [71]. As mentioned in Section 4, a chemometric approach has been applied to study the XANES spectra evolution during in situ scanning of a $\mathrm{Cu}_{0.1} \mathrm{~V}_{2} \mathrm{O}_{5}$ xerogel secondary battery [36].

5.2. Cobalt and Nickel Oxide-Based Materials. Since early research studies in the field of lithium battery around the 80 s, the $\mathrm{LiCoO}_{2}$ layered structure has been widely used as cathode materials since it exhibits good electrochemical capacity [42]. But the drawbacks of such materials such as high cost stimulated the battery communities in search for good alternatives. The isostructural $\mathrm{LiNiO}_{2}$ exhibited an initial capacity of $200 \mathrm{mAh} / \mathrm{g}$, but unlike $\mathrm{LiCoO}_{2}$, it is difficult to prepare with a good reproducibility and stoichiometric quantities. Both $\mathrm{LiCoO}_{2}$ and $\mathrm{LNiO}_{2}$ possess a layered structure where a cubic close packed oxygen array provides twodimensional network of edge shared $\mathrm{Co}(\mathrm{Ni}) \mathrm{O}_{6}$ octahedra for the lithium intercalation/release. The chemical stability and cyclability of these layered electrodes can be obtained by adding a small amount of other elements. Since the year of 2000, a lot of structural studies have been conducted by XAS spectroscopy. One group at Brookhaven was very prolific in this area and conducted several in situ studies [72-76]. In particular, from the XANES curves [72] it was observed that the high-surface-area $\mathrm{Li}_{1-x} \mathrm{Ni}_{0.85} \mathrm{Co}_{0.15} \mathrm{O}_{2}$ cathode material leads to the oxidation of $\mathrm{Ni}^{3+}$ to $\mathrm{Ni}^{4+}$ well before the end of charge $(x \approx 0.85)$ and that the Co atoms do not oxidize during the initial stages but close to the end of charge. In addition, EXAFS [74] showed a reduction in the Jahn-Teller effect during oxidation of $\mathrm{Ni}^{3+}$ to $\mathrm{Ni}^{4+}$, as expected. Similar studies have been conducted on materials doped with $\mathrm{Ga}$ [73], $\mathrm{Al}$ [76], and Fe [77]. Choi et al. [78] also investigated the systematic variations of the $1 \mathrm{~s} \rightarrow 3 \mathrm{~d}$ and $1 \mathrm{~s} \rightarrow 4 \mathrm{p}$ transitions in $\mathrm{Li}_{y} \mathrm{CoO}$ electrode, where the insertion of lithium causes the local structure around Co atoms to become asymmetric. A study from the National Taiwan University of Science and Technology reported on the surface/bulk mechanism of delithiated commercial $\mathrm{LiCoO}_{2}$ cathode [79]. From soft XAS experiment using both total electron yield and fluorescence, it has been demonstrated that the oxidation state of oxygen as well as the electronic transitions on the surface and in the bulk of the delithiated compounds are different. Recently, a combined XAS-RIXS (resonant inelastic X-ray emission) [80] study conducted on $\mathrm{LiNi}_{0.65} \mathrm{Co}_{0.25} \mathrm{Mn}_{0.1} \mathrm{O}_{2}$ material [81] has showed a strong screening behavior of the Li ions between the oxide layers, and an XAS study has been conducted on $\mathrm{LiCoO}_{2}$ particles with nanoscale [82].

5.3. Spinel $\mathrm{LiMn}_{2} \mathrm{O}_{4}$ and Other Manganese Oxide SpinelBased Systems. The relative abundance of manganese has aroused the interest of developing cathode materials based on $\mathrm{LiMn}_{2} \mathrm{O}_{4}$ spinel structures, where cubic close packed oxygen provides a three-dimensional array of edge shared $\mathrm{MnO}_{6}$ octahedra for the lithium insertion and release. Unfortunately, this spinel structure suffers from the cooperative JahnTeller distortion by $\mathrm{Mn}^{3+}$ ion which causes the material to undergo a phase transition from cubic to tetragonal, leading to a rapid degradation of the electrode. Layered $\mathrm{LiMnO}_{2}$ has been considered first as an alternative, but it transforms to spinel structure upon cycling. Considerable improvement of cyclability has been reached by substitution of $\mathrm{Mn}$ with transition metals. A certain number of papers appeared in order to study this issue from the structure and charge viewpoint. Yoon et al. [83] studied the electronic structure of electrochemically Li-ion deintercalated $\mathrm{Li}_{1-x} \mathrm{Mn}_{2} \mathrm{O}_{4}$ system for various $\mathrm{Li}$ compositions using soft X-ray absorption spectroscopy (XAS) and Chan looked into the valence change in a surface modified $\mathrm{LiMn}_{2} \mathrm{O}_{4}$ spinel [84]. In the following years a lot of studies have been conducted in electrode materials with spinel structures, where partial substitution of $\mathrm{Mn}$ by another metal has been observed. Cobalt doped $\mathrm{LiMnO}_{2}$ cathode $[85,86]$, copper-nickel [87], nickel-cobalt [88, 89], nickel [90], magnesium-nickel [89], and nickelcobalt-aluminum [90] analogs have also been the subject of extensive XAS studies, using in situ approaches. These studied have suggested that the doping metal plays a key role in maintaining the layered structure during cycling, by creating a mixed oxide phase where all the manganese ions are kept at $\mathrm{Mn}^{4+}$ oxidation state and the doping metal is responsible for the redox properties. This mechanism is called charge compensation and has been further addressed also using soft 
XAS study, as seen in a paper by Yoon et al. [91]. In fact by measuring both hard (at metal K-edge) and soft (at O K-edge) XAS spectra, the relative importance of oxygen involvement in the redox reaction of $\mathrm{Li}_{1-x} \mathrm{Co}_{1 / 3} \mathrm{Ni}_{1 / 3} \mathrm{Mn}_{1 / 3} \mathrm{O}_{2}$ has been investigated, concluding that a large portion of the charge compensation during lithium release is achieved on the oxygen site. Recently, this strategy has been applied to study the redox mechanism of $\mathrm{Li}_{1.16} \mathrm{Ni}_{0.15} \mathrm{Co}_{0.19} \mathrm{Mn}_{0.50} \mathrm{O}_{2}$ positive electrode during the charging and discharging processes [92]. Deb et al. investigated the charge-compensation mechanism and structural perturbations occurred in the system during cycling of layered $\mathrm{LiNi}_{1 / 3} \mathrm{Co}_{1 / 3} \mathrm{Mn}_{1 / 3} \mathrm{O}_{2}$ system by in situ $\mathrm{XAS}$ and proposed a novel electrochemical in situ cell specifically designed for long-term X-ray experiments [93]. The same material has been further investigated by Kim et al. [94]. The electronic and local structures of partially anionsubstituted lithium manganese spinel oxides as positive electrodes for lithium-ion batteries were investigated using XAS [95], clarifying that the good cyclability depends on the anion doping effect. Titanium doped spinel samples were investigated as well $[96,97]$. The element-specific nature of X-ray absorption spectroscopy to reveal the chemical and structural details of a surface treatment in protection of high-capacity cathode materials has been reported [98]. Another report concerns novel lithium-excess manganese layered oxides, which can also be seen as a solid solution of $\mathrm{zLi}_{2} \mathrm{MnO}_{3}$ and (1z) $\mathrm{LiCo}_{1 / 3} \mathrm{Ni}_{1 / 3} \mathrm{Mn}_{1 / 3} \mathrm{O}_{2}$. The paper addressed the uncommon large reversible capacity for the Li-excess manganese layered oxides, which originates from the electrochemical redox reaction of the oxygen molecules at the electrode surface [99]. This study complements the one by Armstrong [100] which suggested that lithium extraction above $4.5 \mathrm{~V}$ is accompanied by a loss of oxygen.

5.4. Lithium Iron Phosphate. $\mathrm{LiFePO}_{4}$ was considered another promising candidate for cathode materials due to its low cost and good safety characteristics. Its structure is olivine, described by a hexagonally close packed oxygen array in which there are $\mathrm{PO}_{4}$ tetrahedra and $\mathrm{FeO}_{6}$ octahedra. This structure is intrinsically a poor electron conductor. Several methods have been developed to improve the conductivity, for instance, by including carbonaceous material and in control of the particle size and also by doping of multivalent cations in substitution of the Fe. XAS studies on the extraction and insertion of lithium in $\mathrm{LiFePO}_{4}$ electrodes [101, 102] have proved the existence of two separated phases for the fully charged and fully discharged materials: $\mathrm{LiFe}^{(\mathrm{II})} \mathrm{PO}_{4}$ corresponding to the initial state of the battery, whereas in the delithiated state $\left(\mathrm{FePO}_{4}\right)$ iron was found to be in the $\mathrm{Fe}$ (III) state. A recent work by Inoue [103] also analyzes the charge of Fe during charge-discharge cycling. These measurements on the $\mathrm{LiFePO}_{4}$ cathode show that the material retains good structural short-range order leading to superior cycling. A recent work examined [104] the changes in electronic structure in the cobalt analogs, $\mathrm{LiCoPO}_{4}$, whereas the amorphous $\mathrm{FePO}_{4}$ material has been studied by Hong et al. [105]. Giorgetti et al. [106] studied the local structure arrangements of submicrocrystalline lithium iron phosphate and its precursors, obtained by sol-gel synthesis. The joint use of XANES and EXAFS taken at $\mathrm{Fe} \mathrm{K}$-edge pointed out the modification of the Fe site during the synthesis steps, indicating that such a material is different from the conventional crystalline $\mathrm{LiFePO}_{4}$ on the short-range order. The $\mathrm{P} \mathrm{K}$-edge in lithium iron phosphate has been used to analyze the electronic structure of the delithiated $\mathrm{Li}_{1-x} \mathrm{FePO}_{4}$ cathode by Yoon. The gradual shifts on the main edge towards higher energy indicated that $\mathrm{P}-\mathrm{O}$ bonds become less covalent. And from the observation of the pre-edge peaks behavior the authors concluded that the electrochemical delithiation results in the hybridization of P $3 d$ states with the Fe $3 d$ states [107]. Recent studies have been conducted addressing the specific role of the vanadium substitution of $\mathrm{Fe}$ in $\mathrm{LiFePO}_{4}$ [108], a report on a mixed Fe-Mg-Mn phosphate electrode [109], the structural study of the $\mathrm{LiFePO}_{4}-\mathrm{LiNiPO}_{4}$ solid solution [110], and the heterogeneous behavior of a composite electrode of $\mathrm{LiFePO}_{4}$ [111]. In addition the enhanced electronic conductivity found in doped samples has encouraged structural studies of delithiated $\mathrm{LiFe}_{0.5} \mathrm{Co}_{0.5} \mathrm{PO}_{4}$ [112], on carbon coated $\mathrm{LiFe}_{0.33} \mathrm{Mn}_{0.67} \mathrm{PO}_{4}$ [113] and on pure $\mathrm{Li}_{3} \mathrm{~V}_{2}\left(\mathrm{PO}_{4}\right)_{3}$ and $\mathrm{Na}_{3} \mathrm{~V}_{2}\left(\mathrm{PO}_{4}\right)_{3}$ materials embedded in a carbon matrix as a candidates for $\mathrm{Li}$ and $\mathrm{Na}$ batteries, respectively. In the latter study, XAS analysis [114] has evidenced small and reversible changes in the interatomic distances of vanadium after the 1st cycle, indicating very rigid structures during alkali metal extraction.

5.5. Miscellanea. Finally, a few papers appeared recently on a wide variety of new intercalation materials using the XAS probe. Due to the potential interest in Mg batteries [115] an in situ study reports the mechanism of electrochemical deposition of magnesium from a precursor, and the reversibility reaction for the new $\mathrm{Na}_{1-x} \mathrm{Ni}_{0.5} \mathrm{Mn}_{0.5} \mathrm{O}_{2}$ material for $\mathrm{Na}$ based battery has been followed by XAS [116]. It has been reported that as sodium ions are extracted, nickel ions are oxidized to the trivalent state while the manganese ions remain electrochemically inactive in the tetravalent state. Sodium cycling performance has been also investigated in $\mathrm{Na}_{0.74} \mathrm{CoO}_{2}$ material [117]. Dominko reported on in situ XAS of $\mathrm{Li}_{2} \mathrm{MnSiO}_{4}$ and $\mathrm{Li}_{2} \mathrm{FeSiO}_{4}$ cathode materials [118], and Cabana on the possibility of using $\mathrm{Li}_{7.9} \mathrm{MnN}_{3.2} \mathrm{O}_{1.6}$ as a new cathode material [119]. The charge-discharge performance of a rechargeable lithium/sulfur battery has been investigated by in situ XAS [120]. The SEI (solid electrochemical interface) formation on electrode has been the subject of two structural investigations [121, 122].

\section{Application to Metal Hexacyanoferrates}

Metal hexacyanoferrates (MHCF), also called bimetallic cyanides, are a class of inorganic polymeric materials which belongs to Prussian Blue (PB), a pigment discovered by a Berlin draper Diesbach [123] in the eghteenth century. Historically, there are two main characteristics of PB: its color, due to the mixed oxidation state of iron, and its zeolitic character which makes the PB a substance capable of taking in and out, or trapping, guest molecules in the cavities of 


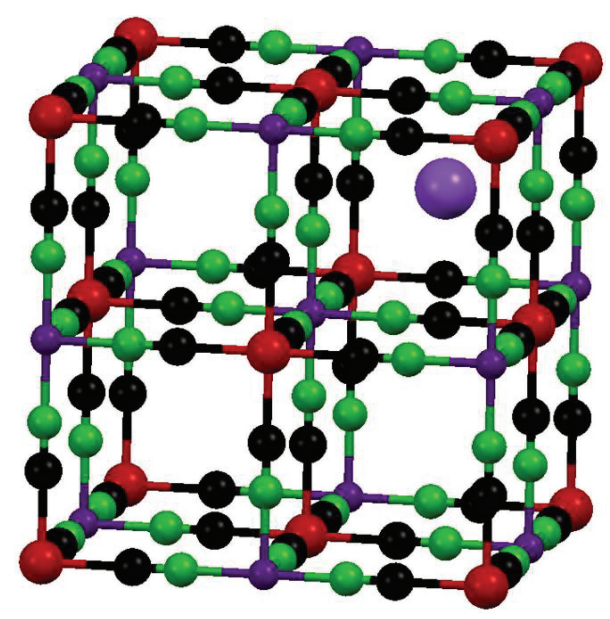

Figure 8: Structure of Prussian Blue analog, that is, metal hexacyanoferrates (MeHCFs). Fe and Me atoms are in the corner of each cube, occupying the $4 \mathrm{a}$ and $4 \mathrm{~b}$ crystallographic sites of the Fm3m space group (soluble structure). Countercations as well as water are placed in the interstitial $8 \mathrm{c}$ position (violet) and can be mobile, giving rise to a wide variety of applications. The insoluble structure is formed when $\mathrm{Fe}(\mathrm{CN})_{6}$ vacancies are present, and the $\mathrm{N}$ empty sites are occupied by $\mathrm{O}$ of coordinated water.

the lattice. From the structural viewpoint these materials are characterized by a rigid three-dimensional cubic network of repeating units of $-\mathrm{NC}-\mathrm{M}_{\mathrm{a}}-\mathrm{CN}-\mathrm{M}_{b}-\mathrm{NC}-$, where $\mathrm{M}_{\mathrm{a}}$ is $\mathrm{Fe}$ in hexacyanoferrates (and it could be other transition metals, in hexacyanometallates) and $\mathrm{M}_{\mathrm{b}}$ is Co and/or Ni and other transition metals [124]. Both $\mathrm{M}_{\mathrm{a}}$ and $\mathrm{M}_{\mathrm{b}}$ sites are typically octahedral, and the sites at the cube centre are occupied by water as well as countercations as necessary to achieve charge neutrality. This regular structure is depicted in Figure 8, and can be referred to as soluble structure, which is described by the space group $F m 3 m$. Depending on the method of preparation, these compounds also feature structural defects. Particularly, the presence of $\mathrm{Fe}(\mathrm{CN})_{6}$ vacancies and the partial occupancy of zeolitic water lead to the so-called insoluble structure, where the $\mathrm{N}$ empty sites are occupied by $\mathrm{O}$ of coordinated water. It is worth pointing out that the term soluble for the $\mathrm{PB}$ actually corresponds to highly insoluble complex, but it gives the appearance of forming a solution in water due to a facile peptization as a blue colloidal sol. Structurally speaking, despite the fact that the majority of PB compounds are cubic, other crystal symmetries are found in few other hexacyanoferrates [125-127].

In the past decade, renewed attention to these materials is based on their use as magnetic devices [128-133]. In fact, the discovery of the photoinduced magnetization in some hexacyanoferrate compounds [134] paved the way to extensive studies. Other properties of the metal hexacyanoferrates are electrochromism, electrocatalysis [135], ion-sieving membranes, charge storage, diffusion properties, corrosion protection, and analytical sensing [136-138]. Among the different preparation methods, hydrothermal synthesis and ultrasonic conditions have been proposed for the preparation of Berlin Green (the oxidized form of PB) microcrystals [139] and PB nanocubes $[140,141]$. Also, nanostructures of cobalt analog of PB has been proposed [142-144].

The structure of MHCFs allows to investigate different phenomena in EXAFS spectroscopy: (i) the multiple scattering; (ii) the multiple-edge data analysis; (iii) the possibility of analyzing molecular complex formed by common structural units which shares same sets of parameters. These aspects will be highlighted here. The peculiarity of MHCF structures of being formed by an almost perfect linear $-\mathrm{NC}-\mathrm{M}_{\mathrm{a}}-\mathrm{CN}-$ $\mathrm{M}_{\mathrm{b}}-\mathrm{NC}-$ atomic chains coupled to a high degeneration of the atomic chains (six in the soluble structure, see Figure 8) and a short distance between $\mathrm{M}_{\mathrm{b}}$ and $\mathrm{M}_{\mathrm{a}}$ (about $5 \AA$ ) produce a strong multiple scattering effect on the EXAFS signal. This has been demonstrated with XANES and EXAFS studies of $\mathrm{Fe}(\mathrm{CN})_{6}{ }^{3-/ 4-}$ ions [145-147] where the multiple scattering signal results are enhanced by the focusing effect [148]. The enhancement of the EXAFS oscillation becomes even more pronounced in the case of four collinear atoms vibrating around the equilibrium positions, and this effect has been called superfocusing [149]. In the late $90 \mathrm{~s} \mathrm{Na}_{2} \mathrm{CoFe}(\mathrm{CN})_{6}$ has been used as prototype of four-body multiple scattering XAFS calculation [149] and a similar study has been conducted on $\mathrm{Co} / \mathrm{Ni}$ hexacyanoferrate [150]. The multiple scattering (MS) formalism represented the best approach for a correct XAS interpretation since the pioneering work by Lee and Pendry [151] and further developed for the EXAFS case by the work of Natoli, Benfatto, and coworkers [152, 153]. A second significant aspect of an EXAFS measurement of MHCFs is evidenced from Figure 4. Due to the contiguous atomic numbers of $\mathrm{Fe}$ and $\mathrm{Co}$, that is, $\mathrm{Z}(\mathrm{Fe}), \mathrm{Z}+1$ (Co), the two metal edges appear very close. In such a case data analysis can be carried out at the two edges simultaneously. This approach has first been applied to the $\mathrm{L}$ edges $\left(\mathrm{L}_{\mathrm{I}}, \mathrm{L}_{\mathrm{II}}\right.$, and $\left.\mathrm{L}_{\mathrm{III}}\right)$ in liquid and crystalline Sn [154] and then extended to the analysis of K-edges by Zhang et al. [155, 156]. It has been called multiple-edge structural refinement. Otherwise, data analysis could be done on the two edges separately. In addition, the high symmetry of MHCFs makes feasible fitting procedures using a reduced number of structural parameters, leading to a very reliable EXAFS minimization. To date, multiple edge approach using some correlated parameters has been reported in the literature [155], and the first example of a multiple edge approach concerning three contiguous metal edges with the peculiar characteristic of sharing the entire structural parameters has been presented by Giorgetti and Berrettoni [150] on nickel/cobalt hexacyanoferrate. The triple probe has allowed extending the number of experimental data to a factor of three (about 1200 from 400), even using the same parameters.

Due to a large Co-N first shell modification of magnetic FeCo cyanides during temperature scan, the use of the XANES and EXAFS probes has become popular in the 90s, with several studies conducted in Japan. The XANES spectrum at both metal edges proved essential in the determination of $\mathrm{Co}^{\mathrm{III}} / \mathrm{Co}^{\mathrm{II}}$ ratio in these molecular complexes, confirming the occurrence of spin transitions [157, 158]. Also, the group of Verdaguer in Paris studied the condition to observe a photoinduced magnetization in several FeCo cyanides with variable amount of Co, by the XAS 
technique [159]. The study was completed with measurements at $\mathrm{L}_{2,3}$ edges [160] and analyzing the role of the $\mathrm{Fe}(\mathrm{CN})_{6}$ vacancies in some cesium derivatives [161]. Combined EXAFS and XANES simulations aimed at checking the vacancies in cobalt hexacyanoferrates have been recently reported [162]. X-ray absorption fine structure spectroscopy has also been used to study the photoinduced magnetic transition in other hexacyanometallates, including FeMn [163], CoW [164], and CuMo [165]. In these studies, even though the EXAFS analyses have been done using single shell fitting procedure and the single edge approach, new data concerning the metal ligand bonding and phase transition have been revealed.

Not only $\mathrm{K}$ lines of metal hexacyanoferrates have been recorded and analyzed in EXAFS experiments but also the $\mathrm{L}$ lines, which gives complementary information concerning the covalency and charge of the metal ligand bond [166]. In particular, it has been evidenced metal-to-ligand charge transfer (MLCT) from 2p XAS spectrum of several bimetallic cyanides [167] has been evidenced, a study concerning the crystal field parameter [168], the specific role of the alkali metal [169], and the study of the electronic configuration of thin film of RbCoFe and $\mathrm{NaCoFe}$ deposited on an $\mathrm{Si}_{3} \mathrm{~N}_{4}$ substrate [170].

Due to the wide application of MCHF in the field of electrochemistry, there has been an extensive use of XAS spectroscopy for the structural characterization of electrode materials. Bulk microcrystals of CoHCF [171], Ni/Co HCF $[172,173]$ cathodical deposits of thin films of NiHCF [174], and $\mathrm{CoHCF}$ in presence of PAMAM doped silica matrix $[175,176]$ have been studied. Those reports demonstrated the suitability of the EXAFS probe to address problems at the chemical/electrochemical interface. An EXAFS study of the electrodeposited Co and Ni hexacyanoferrate films revealed which metal is responsible for the electrochemical response [177]. Recently, a paper presented in-depth studies of $\mathrm{Cu}$ and Fe K-edge thresholds in a series of different electrodeposits of CuHCF on carbon surfaces [178]. The study demonstrates that it is not possible to obtain a "pure" electrosynthesized $\mathrm{CuHCF}$, because a small amount of PB is anyway deposited during the synthesis and a second step consisting of $\mathrm{Cu}^{2+}$ ions intercalation is needed to prepare a more performing material [138]. The inserted copper reaches the defective structural (not interstitial) sites. This conclusion has been extended to deposits on indium tin oxide (ITO) substrates [179].

Bleuzen et al. [180] reported a study using energy dispersive XAS of two FeCo cyanides under variable pressure and room temperature, demonstrating a departure from a cubic symmetry, whereas a phase transition was observed in manganese hexacyanoferrate [181]. Magnetic PB derivatives have been probed by resonant inelastic X-ray scattering [182], revealing the temperature dependence of $\mathrm{Co}$ and $\mathrm{Fe}$ valence ratios in one cooling run. MHCFs have been the subject of soft XAS studies of cyanobridged coordination polymer electrodes [183], Fe and Mn 2p FeMn cyanides [184, 185], and on the origin of $\mathrm{PB}$ fading of several pigments in linseed oil medium [186, 187]. First XAS studies of actinides based metal hexacyanoferrates $[188,189]$ have been reported. Site selective high-resolution $\mathrm{k} \beta$ fluorescence detection has been tested on PB [190] evidencing conformity to the well-known crystallographic distances by Buser et al. [124].

\section{Application to Layered Double Hydroxide and Other Layered Materials}

Layered double hydroxides (LDHs) [191] are a group of synthetic clays which belongs to the naturally occurring mineral hydrotalcite, $\mathrm{Mg}_{6} \mathrm{Al}_{2}(\mathrm{OH})_{6} \mathrm{CO}_{3} 4 \mathrm{H}_{2} \mathrm{O}$, where $\mathrm{Mg}^{2+}$ and $\mathrm{Al}^{3+}$ can be substituted by different trivalent and divalent cations with suitable ionic radii $[192,193]$. Structurally speaking, a positive charges brucite-like layer alternates with anions and water molecules in the unoccupied interlayer. This peculiar structure makes feasible the intercalation and release of various ions and molecules between the brucite-like layers [194], opening applications in various research areas, including catalysis [195, 196], adsorbents [197], electrochemical sensing [198, 199], photochemistry [200], corrosion [201], and environmental remediation [202].

Due to the crystalline nature of LHDs, the structure of pristine materials and successive modification are often monitored and analyzed by means of the X-ray diffraction, where the powder method gives already a fast response concerning the modification of the interlayer spacing upon ions or molecules intercalation/release processes. However, a considerable number of studies appeared in the literature since the pioneering work by Rives et al. [203] concerning the use of X-ray absorption spectroscopy as suitable tools to investigate both structure and charge of the metal ions which constitute the LDH material. In fact, the availability of another metallic site between brucite-like layers of LDH combined with the selectivity of the XAS probe makes these studies not only capable of investigating the local structure of the native metals (i.e., $\mathrm{Ni}$ and $\mathrm{Al}$ in $\mathrm{Ni} / \mathrm{Al} \mathrm{HT}$ ) but also of studying the atomic environment of the guest species at the interlayer. For instance, the sequestration mechanisms of toxic metals such as nickel $(\mathrm{Ni})$, zinc $(\mathrm{Zn})$, and cobalt (Co) in layered double hydroxide (LDH) phases in soils have been examined at $\mathrm{pH} 7.5$ using extended X-ray absorption fine structure spectroscopy (EXAFS) [204], and EXAFS spectroscopic data confirms a coprecipitation mechanism of $\mathrm{Al}$ with $\mathrm{Ni}$ on $\mathrm{Al}$-rich substrates to form $\mathrm{Ni}-\mathrm{Al} \mathrm{LDH}$ surface precipitates [205]. Several studies were related to contaminated soils and remediation procedures [206-208], as for nickel sequestration in kaolinite-humic acid complex [209] and the sorption mechanism of arsenate [210] or nickel $[211,212]$ at molecular level in various matrices. In particular the effect of the humic acid sorption proceeds via formation of mononuclear complexes in Ca-montmorillonites platelets, as evidenced by EXAFS [213]. Also, Zn sorption mechanisms at the clay/mineral interface [214] and on low surface area gibbsite and $\mathrm{Zn} / \mathrm{Al} \mathrm{LDH}$ [215] have been studied as well.

Structural studies by EXAFS spectroscopy on LDHs were aimed at describing the environment of the intercalated ions or molecules, and on the local environment of the $\mathrm{M}^{2+}$ center, thus giving some responses about the possible retaining of the pristine $\mathrm{LDH}$ structure. For instance, the structural site of iodide in $\mathrm{Zn} / \mathrm{Mg} \mathrm{LDH}$ was identified by EXAFS [216], and the same has been done for the oxomolybdenum on $\mathrm{Zn} / \mathrm{Al}$ and 
$\mathrm{Mg} / \mathrm{Al}$ [217], and for lanthanide ion in $\mathrm{Zn} / \mathrm{Al}$ [218] LDHs. An EXAFS analysis confirmed the presence of an Ni-containing $\mathrm{LDH}$ as indicated by the $\mathrm{Ni}-\mathrm{Ni}$ distance and $\mathrm{Ni}$ coordination number in Ni-exchanged $\mathrm{KAlSiO}_{4}$, also confirming the retention of the pristine structure of LHD in $\mathrm{Zn} / \mathrm{Al}$ LHD after insertion of polyoxovanadates [219]. Structural studies during temperature scan highlighted the structural modification occurring in poly (styrene sulfonate) [220] and oxometallate intercalated $\mathrm{Mo} / \mathrm{W} \mathrm{LDH} \mathrm{[221].} \mathrm{Studies} \mathrm{of} \mathrm{the}$ grafting phenomenon $[221,222]$ and calcination at $450^{\circ}$ [223] have been proposed, giving details on the structural evolution of pristine and pillared materials. A study done mainly by extended X-ray absorption fine structure evidenced a cationic order within the sheets of the layered double hydroxide [224]. The synthesis of $\mathrm{Zn} / \mathrm{Cr} \mathrm{LDH}$ has been monitored by EXAFS spectroscopy evidencing the formation of oligomeric species before the LDH signature [225].

Among the various different synthetic approaches, LHDs can be obtained by recovering the layered structure via precipitation from a suitable bath of precursors at moderate temperature. This process leads to amorphous materials mainly, and therefore XAS spectroscopy is the most suitable technique to study both the bulk of materials as well as processes in solutions. Certainly most of the applications of HT correspond to the field of heterogeneous catalysis, where the interlayer space provides unique reaction conditions. Recently, a series of terephthalate-intercalated nickelaluminum LDHs was studied by EXAFS to study the aluminum segregation process, and it was found that the aluminum phase increases continuously with increasing overall aluminum content, becoming significant for values equal to or higher than 0.6 [226]. In addition, Pt and Pt-Cu catalysts for reforming glycerol obtained by calcination of the corresponding $\mathrm{LDH}$ [227] and photocatalysts for water splitting based on $\mathrm{TiO}_{2}$ on LDH matrix [228] have been structurally characterized. $\mathrm{Zn} / \mathrm{Al} \mathrm{LDH}$ obtained by coprecipitation has been used to follow cyclohexene oxidation and monitored by in situ EXAFS/XRD [229].

LHD offered alterative synthesis procedure for layered cathode material [230] and potassium-free nickel hexacyanoferrate [231]. XAS studies have been performed on intercalation of oxocomplexes [232], macrocyclic ligand [233], hexacyanoferrates $[234,235]$, oxometallates [221, 236], and polyoxovanadates [237]. Those papers were aimed at investigate any possible variation of the $\mathrm{Ni}$ local environment in LDH upon the intercalation of the appropriate anion, using XANES measurements taken at the Ni K-edge. The same strategy has evidenced the retaining of the local structural site of $\mathrm{Ni}$ in $\mathrm{Au}$ nanoparticles formation assisted by LDH [238]. Hydrolysis and synthesis conditions of $\mathrm{Ni} / \mathrm{Ga} \mathrm{LDH}$ have been studied by different techniques, including XAS [239-241]. LHDs have also been used to develop urea biosensors for medical diagnosis. An EXAFS study has been conducted in $\mathrm{Zn} / \mathrm{Al} \mathrm{LDH}$ materials after immobilization of urease, evidencing that the local ordering of the $\mathrm{LDH}$ layers is retained [204]. The homogeneity of the metal cation distribution in the hydroxide layers has been demonstrated as well [242], and a method for the EXAFS data analysis was proposed in order to demonstrate the $\mathrm{Al}$ and
$\mathrm{Zn}$ discrimination at a similar crystallographic position [243].

Another class of layered materials which has been attracting a great interest for more than half a century is the graphite intercalation compounds (GICs) [244]. The characteristic ordered layered structure of graphite makes available some particular sites for the guest molecules, or ions, giving interesting magnetic and electrical properties. A lot of research has been conducted in this field in the $80 \mathrm{~s}$ and 90s, and several structural studies have been conducted since the pioneering work by Heald and Stern [245] using the newborn spectroscopy XAS. Most of the applications dealt with graphite material with iron compound [246], such as $\mathrm{FeCl}_{3}$ [247] and $\mathrm{FeBr}_{3}$ [248], and also with $\mathrm{Ni}$ [249] and $\mathrm{Au}$ [250] chlorine. Recently, GIC with platinum salt has found application in the field of catalysis. An XANES/EXAFS analysis at the $\mathrm{Pt} \mathrm{L}_{\mathrm{III}}$ edge has demonstrated the +4 oxidation state and an octahedral coordination (with 4 chlorine ligands) for Pt in hexachloroplatinic acid-CIG [251]. The structure of bromine residue was investigated by XAFS in carbons with different degrees of graphitization [252] and the structure of platinum chloride-graphite intercalation compounds $\left(\mathrm{PtCl}_{4}\right.$ GICs) with a stage three was revealed by a combined XRD and EXAFS analysis [253].

$\mathrm{X}$-ray absorption fine structure spectroscopy has also been used to characterize a new class of two-dimensional solids based on thorium organic coordination polymer [254] and silica supported ytterbium oxide [255] giving evidence of a strong interaction between the $\mathrm{YO}_{6}$ octahedron and the $\mathrm{SiO}_{4}$ tetrahedron. Also, new layered oxychalcogenide structures have been synthesized and relationships between the crystal structures and the physical and chemical properties have been highlighted [256]. Layered perovskite structures have been the subject of structural studies by XAS in order to explain the changes in magnetic interactions based on the rotation and on $\mathrm{CoO}$ polyhedra [257], and the chemical lithiation of Aurivillius-type layered perovskite oxide, $\mathrm{Bi}_{4} \mathrm{~T}_{3} \mathrm{O}_{12}$ (BTO), was demonstrated by XAS measurements at $\mathrm{Bi} \mathrm{L}_{\mathrm{III}}$ and Ti K-edges [258]. The distribution of the Ln ions in the layered crystal structure of rare earth substituted $\mathrm{La}_{2} \mathrm{RuO}_{5}$ was determined by EXAFS spectroscopy [259]. Eventually, local lattice distortions in several semiconductor materials, like $\mathrm{YBa}_{2} \mathrm{Cu}_{3} \mathrm{O}_{y}$ single crystals, have been studied by polarized X-ray absorption spectroscopy $[260,261]$ providing new physical insights concerning the out-of-plane $\mathrm{Cu}-\mathrm{O}$ distance.

\section{Perspectives}

Over the last four decades, XAS has progressed from a technique only suitable for specialists to a widely applicable tool, emerging as an incisive probe of the local structure around selected atomic species in solid, liquid, and molecular gases. XAS is nowadays widely recognized as a mature Xray technique, with a wide range of applications across many scientific disciplines. This is especially true in the case of XAS application in the field of intercalation materials because it connects two communities, the chemists and the physicists, who make their experiments in international laboratory 
using synchrotron radiation. Thanks to a steady development of reliable spectrometers at synchrotron radiation light sources all over the world, there are several beamlines nowadays dedicated to the study of batteries materials, and the data recorded have reached an unprecedented quality. Other areas of improvement include the speed of data collection, the use of focused beam [262], the advanced use of the energy dispersive XAS [263], and the simultaneous use of XAS coupled with other analytical techniques, like mass spectrometry and gas chromatography. This particularly suits in the case of operando measurement in catalysis studies.

From the side of data analysis, as structure determination is based on fitting data to structural model, the availability and development of a suitable structural model are crucial issues. The structural model is taken by crystallographic studies when available and it can also be chosen by consideration of spectroscopic and molecular dynamic information. This starting structural model can also be modified during the fitting procedure, and when a variation of more than $15 \%$ $20 \%$ of a structural parameter is observed, the corresponding individual signal is therefore reformulated by an $a b$ initio calculation. This situation becomes typical in inorganic metal complexes when the ligand structure is available but the complex is ill-crystalline or polycrystalline [264, 265]. An interesting approach to obtain a suitable structural model comes from the combination of XAS and molecular dynamic. In this case the EXAFS structure refinement can be supplemented by computational chemistry methods [266-268]. A recent joint EXAFS-molecular dynamics (MD) method has been applied by Roscioni et al. [269] on gold nanoparticles with sizes between 20 and $60 \AA$, where MD simulations closely reproduce the experimentally recorded spectra.

The situation has also improved on a side from new generations of software for data analysis, where programs are now capable of analysing with great efficiency the multiple scattering occurring at the EXAFS portion of the spectrum. Also, the inclusion of multielectron excitation after the main edge and the non-Gaussian distribution for the photoabsorber scatterer pair allow for a better understanding of the materials characteristics. This allows to better assess the structural disorder, that is, intrinsically present in cathodeand anode-based materials.

There are two more considerations. The first is that XAS must be considered as a spectroscopy, not only a technique where several operations are done in a row and similarly for all the experiments. Here, the difference resides in the fact that the EXAFS data should always be interpreted, regardless of the simplicity of the oscillatory portion of the spectrum. It takes time and several structural models for correct interpretation. The simplicity of the structural information provided by the EXAFS, the oscillations, is also the main weakness of this spectroscopy: as long as a suitable structural model has not been built, the oscillation can be interpreted in too many different ways. Finally, one may completely share the sentence with Miller [13] which underlines the difficulty for newcomers to learn how to conduct XAS experiments and to perform an appropriate data analysis by themselves. The suggestion is that new users, at least in their first attempt to use this spectroscopy, should seek the advice and collaboration of experts who will share their knowledge. This is particularly true in the case of XAS studies on the subject of batteries due to the multidisciplinary knowledge.

\section{Acknowledgments}

The author wishes to thank several colleagues and friends who first taught and shared their interest in XAS spectroscopy and for their efforts and encouragements: S. Stizza, M. Berrettoni, and A. Di Cicco (University of Camerino) and I. Ascone (LURE, Université de Paris-Sud, Orsay) and those who have made possible the applications in the field of battery materials: R. Marassi (University of Camerino), W. H. Smyrl (University of Minnesota), and S. Passerini (now at University of Munster).

\section{References}

[1] W. C. Rontgen, “On a new kind of rays," Nature, vol. 1369, no. 53, pp. 274-276, 1896.

[2] C. J. Benmore, "A review of high energy X-ray diffraction from glasses and liquids," ISRN Materials Science, vol. 2012, Article ID 852905, 19 pages, 2012.

[3] M. West, A. T. Ellis, P. J. Potts et al., "Atomic spectrometry update-X-ray fluorescence spectrometry," Journal of Analytical Atomic Spectrometry, vol. 26, no. 10, pp. 1919-1963, 2011.

[4] D. E. Sayers, E. A. Stern, and F. W. Lytle, "New technique for investigating noncrystalline structures: Fourier analysis of the extended x-ray-absorption fine structure," Physical Review Letters, vol. 27, no. 18, pp. 1204-1207, 1971.

[5] E. A. Stern, "Theory of the extended x-ray-absorption fine structure," Physical Review B, vol. 10, no. 8, pp. 3027-3037, 1974.

[6] D. C. Koningsberger and R. Prins, "X-ray absorption: principles, applications, techniques of EXAFS, SEXAFS, and XANES," in Chemical Analysis, vol. 92, John Wiley \& Sons, New York, NY, USA, 1988.

[7] E. A. Stern and S. M. Heald, "Basic principles and applications of EXAFS," in Handbook of Synchrotron Radiation, E. E. Koch, Ed., pp. 995-1014, North-Holland, Amsterdam, The Netherlands, 1983.

[8] G. Bunker, Introduction to XAFS: A Practical Guide to X-Ray Absorption Fine Structure Spectroscopy, Cambridge University Press, Cambridge, UK, 2010.

[9] F. Hippert, E. Geissler, J. L. Hodeau, E. Lelièvre-Berna, and J. R. Regnard, Neutron and X-Ray Spectroscopy, Springer, Amsterdam, The Netherlands, 2006.

[10] J. J. Rehr and R. C. Albers, "Theoretical approaches to X-ray absorption fine structure," Reviews of Modern Physics, vol. 72, no. 3, pp. 621-892, 2000.

[11] A. Filipponi, "EXAFS for liquids," Journal of Physics, vol. 13, no. 7, pp. R23-R60, 2001.

[12] X. Carrier, E. Marceau, H. Carabineiro, V. Rodríguez-González, and M. Che, "EXAFS spectroscopy as a tool to probe metalsupport interaction and surface molecular structures in oxidesupported catalysts: application to $\mathrm{Al}_{2} \mathrm{O}_{3}$-supported $\mathrm{Ni}(\mathrm{II})$ complexes and $\mathrm{ZrO}_{2}$-supported tungstates," Physical Chemistry Chemical Physics, vol. 11, no. 35, pp. 7527-7539, 2009.

[13] R. C. Nelson and J. T. Miller, "An introduction to X-ray absorption spectroscopy and its in situ application to organometallic compounds and homogeneous catalysts," Catalysis Science \& Technology, vol. 2, no. 3, pp. 461-470, 2012. 
[14] H. D. Dewald, "Use of EXAFS to probe electrode-solution interfaces," Electroanalysis, vol. 3, no. 3, pp. 145-155, 1991.

[15] I. Ascone, R. Fourme, and S. S. Hasnain, "X-ray absorption spectroscopy and structural genomics," Journal of Synchrotron Radiation, vol. 10, no. 1, pp. 1-111, 2003.

[16] "Synchrotron radiation in inorganic and bioinorganic chemistry," Coordination Chemistry Reviews, vol. 249, no. 1-2, pp. 1272, 2005.

[17] J. Als-Nielsen and D. McMorrow, Elements of Modern X-Ray Physics, John Wiley \& Sons, Chichester, UK, 2nd edition, 2011.

[18] F. de Groot, G. Vankó, and P. Glatzel, “The 1s X-ray absorption pre-edge structures in transition metal oxides," Journal of Physics, vol. 21, no. 10, Article ID 104297, 2009.

[19] T. E. Westre, P. Kennepohl, J. G. DeWitt, B. Hedman, K. O. Hodgson, and E. I. Solomon, "A multiplet analysis of Fe K-edge $1 \mathrm{~s} \rightarrow 3 \mathrm{~d}$ pre-edge features of iron complexes," Journal of the American Chemical Society, vol. 119, no. 27, pp. 6297-6314, 1997.

[20] A. Manceau, A. I. Gorshkov, and V. A. Drits, "Structural chemistry of $\mathrm{Mn}, \mathrm{Fe}, \mathrm{Co}$, and $\mathrm{Ni}$ in manganese hydrous oxides: part I. Information from XANES spectroscopy," American Mineralogist, vol. 77, no. 11-12, pp. 1133-1143, 1992.

[21] G. Giuli, S. G. Eeckhout, E. Paris, C. Koeberl, and G. Pratesi, "Iron oxidation state in impact glass from the K/T boundary at Beloc, Haiti, by high-pressure XANES spectroscopy," Meteoritics and Planetary Science, vol. 40, no. 11, pp. 1575-1580, 2005.

[22] Z. Y. Wu, D. C. Xian, T. D. Hu et al., "Quadrupolar transitions and medium-range-order effects in metal K-edge X-ray absorption spectra of 3d transition-metal compounds," Physical Review B, vol. 70, no. 3, Article ID 033104, pp. 1-33104, 2004.

[23] T. Yamamoto, "Assignment of pre-edge peaks in K-edge x-ray absorption spectra of $3 \mathrm{~d}$ transition metal compounds: electric dipole or quadrupole?” X-Ray Spectrometry, vol. 37, no. 6, pp. 572-584, 2008.

[24] L. R. Sharpe, W. R. Heineman, and R. C. Elder, "EXAFS spectroelectrochemistry," Chemical Reviews, vol. 90, no. 5, pp. 705-722, 1990.

[25] M. Newville, "IFEFFIT: interactive XAFS analysis and FEFF fitting," Journal of Synchrotron Radiation, vol. 8, no. 2, pp. 322324, 2001.

[26] M. Benfatto, S. D. Longa, and C. R. Natoli, "The MXAN procedure: a new method for analysing the XANES spectra of metalloproteins to obtain structural quantitative information," Journal of Synchrotron Radiation, vol. 10, no. 1, pp. 51-57, 2003.

[27] Y. Joly, "X-ray absorption near-edge structure calculations beyond the muffin-tin approximation," Physical Review B, vol. 63, no. 12, Article ID 125120, pp. 1251201-12512010, 2001.

[28] E. Stavitski and F. M. F. de Groot, "The CTM4XAS program for EELS and XAS spectral shape analysis of transition metal L edges," Micron, vol. 41, no. 7, pp. 687-694, 2010.

[29] A. Filipponi, A. Di Cicco, and C. R. Natoli, "X-ray-absorption spectroscopy and n-body distribution functions in condensed matter. I. Theory," Physical Review B, vol. 52, no. 21, pp. 1512215134, 1995.

[30] A. Filipponi and A. Di Cicco, "X-ray-absorption spectroscopy and n-body distribution functions in condensed matter. II. Data analysis and applications," Physical Review B, vol. 52, no. 21, pp. 15135-15149, 1995.

[31] A. L. Ankudinov, B. Ravel, J. J. Rehr, and S. D. Conradson, "Realspace multiple-scattering calculation and interpretation of $\mathrm{x}$ ray-absorption near-edge structure," Physical Review B, vol. 58, no. 12 , pp. $7565-7576,1998$.
[32] J. J. Rehr, J. Mustre de Leon, S. I. Zabinsky, and R. C. Albers, "Theoretical X-ray absorption fine structure standards," Journal of the American Chemical Society, vol. 113, no. 14, pp. 5135-5140, 1991.

[33] N. Binsted, R. W. Strange, and S. S. Hasnain, "Constrained and restrained refinement in EXAFS data analysis with curved wave theory," Biochemistry, vol. 31, no. 48, pp. 12117-12125, 1992.

[34] S. Tomi, B. G. Searle, A. Wander et al., "New tools for the analysis of EXAFS: the DL EXCURV package," CCLRC Technical Report DL-TR-2005-001.

[35] J. J. Rehr, J. J. Kas, F. D. Vila, M. P. Prange, and K. Jorissen, "Parameter-free calculations of X-ray spectra with FEFF9," Physical Chemistry Chemical Physics, vol. 12, no. 21, pp. 55035513, 2010.

[36] P. Conti, S. Zamponi, M. Giorgetti, M. Berrettoni, and W. H. Smyrl, "Multivariate curve resolution analysis for interpretation of dynamic $\mathrm{Cu}$ k-edge X-ray absorption spectroscopy spectra for a $\mathrm{Cu}$ doped $\mathrm{V}_{2} \mathrm{O}_{5}$ lithium battery," Analytical Chemistry, vol. 82, no. 9, pp. 3629-3635, 2010.

[37] B. K. Lavine and J. Workman Jr., "Chemometrics," Analytical Chemistry, vol. 85, no. 2, pp. 705-714, 2013.

[38] J. M. Tarascon and M. Armand, "Issues and challenges facing rechargeable lithium batteries," Nature, vol. 414, no. 6861, pp. 359-367, 2001.

[39] J. B. Goodenough and Y. Kim, "Challenges for rechargeable Li batteries," Chemistry of Materials, vol. 22, no. 3, pp. 587-603, 2010.

[40] M. Winter and R. J. Brodd, "What are batteries, fuel cells, and supercapacitors?" Chemical Reviews, vol. 104, no. 10, pp. 42454269, 2004.

[41] M. S. Whittingham, "Lithium batteries and cathode materials," Chemical Reviews, vol. 104, no. 10, pp. 4271-4301, 2004.

[42] B. L. Ellis, K. Tae Lee, and L. F. Nazar, "Positive electrode materials for Li-ion and Li-batteries," Chemistry of Materials, vol. 22, no. 3, pp. 691-714, 2010.

[43] J. W. Long, B. Dunn, D. R. Rolison, and H. S. White, "Threedimensional battery architectures," Chemical Reviews, vol. 104, no. 10, pp. 4463-4492, 2004.

[44] J. Mc Breen, W. E. O'Grady, and K. I. Pandya, "EXAFS: a new tool for the study of battery and fuel cell materials," Journal of Power Sources, vol. 22, no. 3-4, pp. 323-340, 1988.

[45] M. F. Toney and J. McBreen, "In situ synchrotron X-ray techniques for determining atomic structure at electrode/electrolyte interfaces," Electrochemical Society Interface, vol. 2, no. 1, pp. 2231, 1993.

[46] M. Balasubramanian, X. Sun, X. Q. Yang, and J. McBreen, "In situ X-ray diffraction and X-ray absorption studies of high-rate lithium-ion batteries," Journal of Power Sources, vol. 92, no. 1-2, pp. 1-8, 2001

[47] J. B. Leriche, S. Hamelet, J. Shu et al., "An electrochemical cell for operando study of lithium batteries using synchrotron radiation," Journal of the Electrochemical Society, vol. 157, no. 5, pp. A606-A610, 2010.

[48] J. B. Leriche, S. Hamelet, J. Shu et al., "An electrochemical cell for operand study of lithium batteries using synchrotron radiation," Journal of the Electrochemical Society, vol. 157, no. 5, pp. A606A610, 2010.

[49] P. Shearing, Y. Wu, S. J. Harris, and N. Brandon, "In situ X-ray spectroscopy and imaging of battery materials," Electrochemical Society Interface, vol. 20, no. 3, pp. 43-47, 2011. 
[50] N. A. Chernova, M. Roppolo, A. C. Dillon, and M. S. Whittingham, "Layered vanadium and molybdenum oxides: batteries and electrochromics," Journal of Materials Chemistry, vol. 19, no. 17, pp. 2526-2552, 2009.

[51] J. Wong, F. W. Lytle, R. P. Messmer, and D. H. Maylotte, "K-edge absorption spectra of selected vanadium compounds," Physical Review B, vol. 30, no. 10, pp. 5596-5610, 1984.

[52] C. Cartier, A. Tranchant, M. Verdaguer, R. Messina, and H. Dexpert, "X-ray diffraction and X-ray absorption studies of the structural modifications induced by electrochemical lithium intercalation into $\mathrm{V}_{2} \mathrm{O}_{5}$," Electrochimica Acta, vol. 35, no. 5, pp. 889-898, 1990.

[53] E. Prouzet, C. C. Dit Moulin, F. Villain, and A. Tranchant, "Electrochemical intercalation of lithium into vanadium pentaoxide: an in situ X-ray absorption study," Journal of the Chemical Society, vol. 92, no. 1, pp. 103-109, 1996.

[54] R. Tossici, R. Marassi, M. Berrettoni, S. Stizza, and G. Pistoia, "Study of amorphous and crystalline $\mathrm{Li}_{1+x} \mathrm{~V}_{3} \mathrm{O}_{8}$ by FTIR, XAS and electrochemical techniques," Solid State Ionics, vol. 57, no. 3-4, pp. 227-234, 1992.

[55] R. Tossici, R. Marassi, M. Berrettoni, S. Stizza, and G. Pistoia, "Electrochemical, ZAS and FTIR study of lithium intercalation in $\mathrm{Na}_{1+x} \mathrm{~V}_{3} \mathrm{O}_{3}$," Solid State Ionics, vol. 67, no. 1-2, pp. 77-83, 1993.

[56] P. E. Stallworth, S. Kostov, M. L. DenBoer, S. G. Greenbaum, and C. Lampe-Onnerud, "X-ray absorption and magnetic resonance spectroscopic studies of $\mathrm{Li}_{x} \mathrm{~V}_{6} \mathrm{O}_{13}$," Journal of Applied Physics, vol. 83, no. 3, pp. 1247-1255, 1998.

[57] Y. Piffard, F. Leroux, D. Guyomard, J. L. Mansot, and M. Tournoux, "The amorphous oxides $\mathrm{MnV}_{2} \mathrm{O}_{6}+\delta(0<\delta<1)$ as high capacity negative electrode materials for lithium batteries," Journal of Power Sources, vol. 68, no. 2, pp. 698-703, 1997.

[58] S. Passerini, D. B. Le, W. H. Smyrl et al., "XAS and electrochemical characterization of lithiated high surface area $\mathrm{V}_{2} \mathrm{O}_{5}$ aerogels," Solid State Ionics, vol. 104, no. 3-4, pp. 195-204, 1997.

[59] M. Giorgetti, S. Passerini, W. H. Smyrl, S. Mukerjee, X. Q. Yang, and J. McBreen, "In situ X-ray absorption spectroscopy characterization of $\mathrm{V}_{2} \mathrm{O}_{5}$ xerogel cathodes upon lithium intercalation," Journal of the Electrochemical Society, vol. 146, no. 7, pp. 23872392, 1999.

[60] A. N. Mansour, P. H. Smith, W. M. Baker, M. Balasubramanian, and J. McBreen, "A comparative in situ X-ray absorption spectroscopy study of nanophase $\mathrm{V}_{2} \mathrm{O}_{5}$ aerogel and ambigel cathodes," Journal of the Electrochemical Society, vol. 150, no. 4, pp. A403-A413, 2003.

[61] A. N. Mansour, P. H. Smith, W. M. Baker, M. Balasubramanian, and J. McBreen, "In situ XAS investigation of the oxidation state and local structure of vanadium in discharged and charged $\mathrm{V}_{2} \mathrm{O}_{5}$ aerogel cathodes," Electrochimica Acta, vol. 47, no. 19, pp. 3151-3161, 2002.

[62] C. Rossignol and G. Ouvrard, "General behavior upon cycling of LiNiVO4 as battery electrode," Journal of Power Sources, vol. 97-98, pp. 491-493, 2001.

[63] M. Giorgetti, S. Passerini, W. H. Smyrl, and M. Berrettoni, "Evidence of bilayer structure in $\mathrm{V}_{2} \mathrm{O}_{5}$ xerogel," Inorganic Chemistry, vol. 39, no. 7, pp. 1514-1517, 2000.

[64] M. Giorgetti, M. Berrettoni, S. Passerini, and W. H. Smyrl, "Absorption of polarized X-rays by $\mathrm{V}_{2} \mathrm{O}_{5}$-based cathodes for lithium batteries: an application," Electrochimica Acta, vol. 47, no. 19, pp. 3163-3169, 2002.

[65] M. Giorgetti, S. Passerini, M. Berrettoni, and W. H. Smyrl, "XAS investigation on polyvalent cation intercalation in $\mathrm{V}_{2} \mathrm{O}_{5}$ aerogels," Journal of Synchrotron Radiation, vol. 6, no. 3, pp. 743$745,1999$.

[66] W. H. Smyrl, S. Passerini, M. Giorgetti, F. Coustier, M. M. Fay, and B. B. Owens, "Electrochemical and synchrotron XAS studies of lithium intercalation into vanadium pentoxide aerogels and nanocomposites," Journal of Power Sources, vol. 97-98, pp. 469-472, 2001.

[67] M. Giorgetti, S. Passerini, W. H. Smyrl, and M. Berrettoni, "Identification of an unconventional zinc coordination site in anhydrous $\mathrm{Zn}_{x} \mathrm{~V}_{2} \mathrm{O}_{5}$ aerogels from $\mathrm{x}$-ray absorption spectroscopy," Chemistry of Materials, vol. 11, no. 8, pp. 2257-2264, 1999.

[68] E. Frabetti, G. A. Deluga, W. H. Smyrl, M. Giorgetti, and M. Berrettoni, "X-ray absorption spectroscopy study of $\mathrm{Cu}_{0.25} \mathrm{~V}_{2} \mathrm{O}_{5}$ and $\mathrm{Zn}_{0.25} \mathrm{~V}_{2} \mathrm{O}_{5}$ aerogel-like cathodes for lithium batteries," Journal of Physical Chemistry B, vol. 108, no. 12, pp. 3765-3771, 2004.

[69] M. Giorgetti, S. Mukerjee, S. Passerini, J. McBreen, and W. H. Smyrl, "Evidence for reversible formation of metallic $\mathrm{Cu}$ in $\mathrm{Cu}_{0.1} \mathrm{~V}_{2} \mathrm{O}_{5}$ xerogel cathodes during intercalation cycling of $\mathrm{Li}+$ ions as detected by X-ray absorption spectroscopy," Journal of the Electrochemical Society, vol. 148, no. 7, pp. A768-A774, 2001.

[70] M. Giorgetti, M. Berrettoni, and W. H. Smyrl, "Doped $\mathrm{V}_{2} \mathrm{O}_{5}$ based cathode materials: where does the doping metal go? An X-ray absorption spectroscopy study," Chemistry of Materials, vol. 19, no. 24, pp. 5991-6000, 2007.

[71] H. C. Choi, Y. M. Jung, and S. B. Kim, "Characterization of the electrochemical reactions in the $\mathrm{Li} 1+\mathrm{xV} 3 \mathrm{O} 8 / \mathrm{Li}$ cell by soft $\mathrm{X}$ ray absorption spectroscopy and two-dimensional correlation analysis," Applied Spectroscopy, vol. 57, no. 8, pp. 984-990, 2003.

[72] M. Balasubramanian, X. Sun, X. Q. Yang, and J. McBreen, "In situ X-ray absorption studies of a high-rate $\mathrm{LiNi}_{0.85} \mathrm{Co}_{0.15} \mathrm{O}_{2}$ cathode material," Journal of the Electrochemical Society, vol. 147, no. 8, pp. 2903-2909, 2000.

[73] M. Balasubramanian, J. McBreen, K. Pandya, and K. Amine, "Local structure of dilute gallium ions in $\mathrm{LiNi}_{0.908} \mathrm{Co}_{0.085}$ $\mathrm{Ga}_{0.003} \mathrm{O}_{2}$ cathode material in situ X-ray absorption study," Journal of the Electrochemical Society, vol. 149, no. 9, pp. A1246A1249, 2002.

[74] M. Balasubramanian, X. Sun, X. Q. Yang, and J. McBreen, "In situ X-ray absorption studies of a high-rate $\mathrm{LiNi}_{0.85} \mathrm{Co}_{0.15} \mathrm{O}_{2}$ cathode material," Journal of the Electrochemical Society, vol. 147, no. 8, pp. 2903-2909, 2000.

[75] D. P. Abraham, R. D. Twesten, M. Balasubramanian et al., "Microscopy and spectroscopy of lithium nickel oxide-based particles used in high power lithium-ion cells," Journal of the Electrochemical Society, vol. 150, no. 11, pp. A1450-A1456, 2003.

[76] W. S. Yoon, K. Y. Chung, J. McBreen, D. A. Fischer, and X. Q. Yang, "Electronic structural changes of the electrochemically Li-ion deintercalated $\mathrm{LiNi}_{0.8} \mathrm{Co}_{0.15} \mathrm{Al}_{0.05} \mathrm{O}_{2}$ cathode material investigated by X-ray absorption spectroscopy," Journal of Power Sources, vol. 174, no. 2, pp. 1015-1020, 2007.

[77] A. N. Mansour, L. Croguennec, G. Prado, and C. Delmas, "In situ XAS study of $\mathrm{Li}_{x} \mathrm{Ni}_{0.7} \mathrm{Fe}_{0.15} \mathrm{Co}_{0.15} \mathrm{O}_{2}$ cathode material," Journal of Synchrotron Radiation, vol. 8, no. 2, pp. 866-868, 2001.

[78] H. C. Choi, S. Y. Lee, S. B. Kim et al., "Local structural characterization for electrochemical insertion-extraction of lithium into $\mathrm{CoO}$ with X-ray absorption spectroscopy," Journal of Physical Chemistry B, vol. 106, no. 36, pp. 9252-9260, 2002.

[79] C. H. Chen, B. J. Hwang, C. Y. Chen et al., "Soft X-ray absorption spectroscopy studies on the chemically delithiated commercial 
$\mathrm{LiCoO}_{2}$ cathode material," Journal of Power Sources, vol. 174, no. 2, pp. 938-943, 2007.

[80] A. Kotani and S. Shin, "Resonant Inelastic X-ray scattering for electrons in solids," Reviews of Modern Physics, vol. 73, no. 1, pp. 203-246, 2001.

[81] H. M. Hollmark, L. C. Duda, M. Dahbi, I. Saadoune, T. Gustafsson, and K. Edström, "Resonant soft X-ray emission spectroscopy and $\mathrm{X}$-ray absorption spectroscopy on the cathode material $\mathrm{LiNi}_{0.65} \mathrm{Co}_{0.25} \mathrm{Mn}_{0.1} \mathrm{O}_{2}$," Journal of the Electrochemical Society, vol. 157, no. 8, pp. A962-A966, 2010.

[82] L. Maugeri, A. Iadecola, B. Joseph et al., "Local structure of $\mathrm{LiCoO}_{2}$ nanoparticles studied by Co K-edge X-ray absorption spectroscopy," Journal of Physics Condensed Matter, vol. 24, no. 33, Article ID 335305, 2012.

[83] W. S. Yoon, K. Y. Chung, K. H. Oh, and K. B. Kim, “Changes in electronic structure of the electrochemically Li-ion deintercalated LiMn2O4 system investigated by soft X-ray absorption spectroscopy," Journal of Power Sources, vol. 119-121, pp. 706709, 2003.

[84] H. W. Chan, J. G. Duh, and J. F. Lee, "Valence change by in situ XAS in surface modified LiMn2O4 for Li-ion battery," Electrochemistry Communications, vol. 8, no. 11, pp. 1731-1736, 2006.

[85] B. J. Hwang, Y. W. Tsai, R. Santhanam et al., "Evolution of local electronic and atomic structure of Co-doped LiMn2O4 cathode material for lithium rechargeable batteries," Journal of Power Sources, vol. 123, no. 2, pp. 206-215, 2003.

[86] J. Bareño, M. Balasubramanian, S. H. Kang et al., "Long-range and local structure in the layered oxide $\mathrm{Li}_{1.2} \mathrm{Co}{ }_{0.4} \mathrm{Mn}_{0.4} \mathrm{O}_{2}$," Chemistry of Materials, vol. 23, no. 8, pp. 2039-2050, 2011.

[87] S. Mukerjee, X. Q. Yang, X. Sun, S. J. Lee, J. McBreen, and Y. Ein-Eli, "In situ synchrotron X-ray studies on copper-nickel 5 V Mn oxide spinel cathodes for Li-ion batteries," Electrochimica Acta, vol. 49, no. 20, pp. 3373-3382, 2004.

[88] A. Deb, U. Bergmann, S. P. Cramer, and E. J. Cairns, "In situ X-ray absorption spectroscopic study of $\mathrm{Li}_{1.05} \mathrm{Ni}_{0.35} \mathrm{Co}_{0.25}$ $\mathrm{Mn}_{0.4} \mathrm{O}_{2}$ cathode material coated with $\mathrm{LiCoO}_{2}$," Journal of the Electrochemical Society, vol. 154, no. 6, pp. A534-A541, 2007.

[89] U. Lafont, C. Locati, W. J. H. Borghols et al., "Nanosized high voltage cathode material $\mathrm{LiMg}_{0.05} \mathrm{Ni}_{0.45} \mathrm{Mn}_{1.5} \mathrm{O}_{4}$ : structural, electrochemical and in situ investigation," Journal of Power Sources, vol. 189, no. 1, pp. 179-184, 2009.

[90] C. Rumble, T. E. Conry, M. Doeff, E. J. Cairns, J. E. PennerHahn, and A. Deb, "Structural and electrochemical investigation of $\mathrm{Li}\left(\mathrm{Ni}_{0.4} \mathrm{Co}_{0.15} \mathrm{Al}_{0.05} \mathrm{Mn}_{0.4}\right) \mathrm{O}_{2}$ cathode material," Journal of the Electrochemical Society, vol. 157, no. 12, pp. A1317-A1322, 2010.

[91] W. S. Yoon, M. Balasubramanian, K. Y. Chung et al., "Investigation of the charge compensation mechanism on the electrochemically Li-ion deintercalated $\mathrm{Li}_{1-x} \mathrm{Co}_{1 / 3} \mathrm{Ni}_{1 / 3} \mathrm{Mn}_{1 / 3} \mathrm{O}_{2}$ electrode system by combination of soft and hard X-ray absorption spectroscopy," Journal of the American Chemical Society, vol. 127, no. 49, pp. 17479-17487, 2005.

[92] M. Oishi, T. Fujimoto, Y. Takanashi et al., "Charge compensation mechanisms in $\mathrm{Li}_{1.16} \mathrm{Ni}_{0.15} \mathrm{Co}_{0.19} \mathrm{Mn}_{0.50} \mathrm{O}_{2}$ positive electrode material for Li-ion batteries analyzed by a combination of hard and soft X-ray absorption near edge structure," Journal of Power Sources, vol. 222, pp. 45-51, 2013.

[93] A. Deb, U. Bergmann, S. P. Cramer, and E. J. Cairns, "In situ X-ray absorption spectroscopic study of the $\mathrm{Li}$ $\left[\mathrm{Ni}_{1 / 3} \mathrm{Co}_{1 / 3} \mathrm{Mn}_{1 / 3}\right] \mathrm{O}_{2}$ cathode material," Journal of Applied Physics, vol. 97, no. 11, Article ID 113523, pp. 1-11, 2005.
[94] M. G. Kim, H. J. Shin, J. H. Kim, S. H. Park, and Y. K. Sun, "XAS investigation of inhomogeneous metal-oxygen bond covalency in bulk and surface for charge compensation in Li-ion battery cathode $\mathrm{Li}\left[\mathrm{Ni}_{1 / 3} \mathrm{Co}_{1 / 3} \mathrm{Mn}_{1 / 3}\right] \mathrm{O}_{2}$ Material," Journal of the Electrochemical Society, vol. 152, no. 7, pp. A1320-A1328, 2005.

[95] T. Okumura, T. Fukutsuka, K. Matsumoto et al., "Role of local and electronic structural changes with partially anion substitution Lithium manganese spinel oxides on their electrochemical properties: X-ray absorption spectroscopy study," Dalton Transactions, vol. 40, no. 38, pp. 9752-9764, 2011.

[96] C. S. Johnson, J. S. Kim, A. Jeremy Kropf, A. J. Kahaian, J. T. Vaughey, and M. M. Thackeray, "The role of $\mathrm{Li}_{2} \mathrm{MO}_{2}$ structures $\left(\mathrm{M}=\right.$ metal ion) in the electrochemistry of $(\mathrm{x}) \mathrm{LiMn}_{0.5} \mathrm{Ni}_{0.5} \mathrm{O}_{2}$. (1-x) $\mathrm{Li}_{2} \mathrm{TiO}_{3}$ electrodes for lithium-ion batteries," Electrochemistry Communications, vol. 4, no. 6, pp. 492-498, 2002.

[97] C. S. Johnson, J. S. Kim, A. J. Kropf, A. J. Kahaian, J. T. Vaughey, and M. M. Thackeray, "Structural and electrochemical evaluation of (1-x)Li2TiO3.(x)LiMn0.5Ni0.5O 2 electrodes for lithium batteries," Journal of Power Sources, vol. 119-121, pp. 139144, 2003.

[98] J. R. Croy, M. Balasubramanian, D. Kim, S. H. Kang, and M. Thackeray, "Designing high-capacity, lithium-ion cathodes using X-ray absorption spectroscopy," Chemistry of Materials, vol. 23, no. 24, pp. 5415-5424, 2011.

[99] N. Yabuuchi, K. Yoshii, S. T. Myung, I. Nakai, and S. Komaba, "Detailed studies of a high-capacity electrode material for rechargeable batteries, $\mathrm{Li}_{2} \mathrm{MnO}_{3}-\mathrm{LiCo}_{1 / 3} \mathrm{Ni}_{1 / 3} \mathrm{Mn}_{1 / 3} \mathrm{O}_{2}$," Journal of the American Chemical Society, vol. 133, no. 12, pp. 44044419, 2011.

[100] A. R. Armstrong, M. Holzapfel, P. Novák et al., "Demonstrating oxygen loss and associated structural reorganization in the lithium battery cathode $\mathrm{Li}\left[\mathrm{Ni}_{0.2} \mathrm{Li}_{0.2} \mathrm{Mn}_{0.6}\right] \mathrm{O}_{2}$," Journal of the American Chemical Society, vol. 128, no. 26, pp. 8694-8698, 2006.

[101] O. Haas, A. Deb, E. J. Cairns, and A. Wokaun, "Synchrotron X-ray absorption study of LiFePO4 electrodes," Journal of the Electrochemical Society, vol. 152, no. 1, pp. A191-A196, 2005.

[102] A. Deb, U. Bergmann, E. J. Cairns, and S. P. Cramer, "X-ray absorption spectroscopy study of the $\mathrm{Li}_{x} \mathrm{FePO}_{4}$ cathode during cycling using a novel electrochemical in situ reaction cell," Journal of Synchrotron Radiation, vol. 11, no. 6, pp. 497-504, 2004.

[103] K. Inoue, S. Fujieda, K. Shinoda, S. Suzuki, and Y. Waseda, "Chemical state of Iron of LiFePO4during charge-discharge cycles studied by in-situ X-ray absorption spectroscopy," Materials Transactions, vol. 51, no. 12, pp. 2220-2224, 2010.

[104] M. Nakayama, S. Goto, Y. Uchimoto, M. Wakihara, and Y. Kitajima, "Changes in electronic structure between cobalt and oxide ions of lithium cobalt phosphate as $4.8-\mathrm{V}$ positive electrode material," Chemistry of Materials, vol. 16, no. 18, pp. 3399-3401, 2004.

[105] Y. S. Hong, S. R. Kwang, J. P. Yong, G. K. Min, M. L. Jay, and H. C. Soon, "Amorphous FePO4 as $3 \mathrm{~V}$ cathode material for lithium secondary batteries," Journal of Materials Chemistry, vol. 12, no. 6, pp. 1870-1874, 2002.

[106] M. Giorgetti, M. Berrettoni, S. Scaccia, and S. Passerini, "Characterization of sol-gel-synthesized LiFePO4 by multiple scattering XAFS," Inorganic Chemistry, vol. 45, no. 6, pp. 2750-2757, 2006.

[107] W. S. Yoon, K. Y. Chung, J. McBreen, K. Zaghib, and X. Q. Yang, "Electronic structure of the electrochemically delithiated Li 1xFePO4 electrodes investigated by $\mathrm{P}$ K-edge X-ray absorption 
spectroscopy," Electrochemical and Solid-State Letters, vol. 9, no. 9, pp. A415-A417, 2006.

[108] F. Omenya, N. A. Chernova, S. Upreti et al., "Can vanadium be substituted into LiFePO4?" Chemistry of Materials, vol. 23, no. 21, pp. 4733-4740, 2011.

[109] D. Jang, K. Palanisamy, J. Yoon, Y. Kim, and W. -S Yoon, “Crystal and local structure studies of LiFe0. 48Mn0. 48Mg0. 04PO4 cathode material for lithium rechargeable batteries," Journal of Power Sources, 2013.

[110] L. Tabassam, G. Giuli, A. Moretti et al., "Structural study of LiFePO4-LiNiPO4 solid solutions," Journal of Power Sources, vol. 213, pp. 287-295, 2012.

[111] G. Ouvrard, M. Zerrouki, P. Soudan et al., "Heterogeneous behaviour of the lithium battery composite electrode LiFePO4," Journal of Power Sources, vol. 229, pp. 16-31, 2013.

[112] W. S. Yoon, K. Y. Chung, K. W. Nam et al., "Electronic structural changes of the electrochemically delithiated $\mathrm{LiFe} 0.5 \mathrm{Co} 0.5 \mathrm{PO} 4$ cathode material studied by X-ray absorption spectroscopy," Journal of Power Sources, vol. 183, no. 1, pp. 427-430, 2008.

[113] A. Perea, L. Castro, L. Aldon et al., "Study of C-coated liFe0. $33 \mathrm{Mn} 0.67 \mathrm{PO} 4$ as positive electrode material for $\mathrm{Li}$-ion batteries," Journal of Solid State Chemistry, vol. 192, pp. 201-209, 2012.

[114] M. Pivko, I. Arcon, M. Bele, R. Dominko, and M. Gaberscek, " $\mathrm{A}_{3} \mathrm{~V}_{2}\left(\mathrm{PO}_{4}\right)_{3}(\mathrm{~A}=\mathrm{Na}$ or $\mathrm{Li})$ probed by in situ $\mathrm{X}$-ray absorption spectroscopy," Journal of Power Sources, vol. 216, pp. 145-151, 2012.

[115] T. S. Arthur, P.-A. Glans, M. Matsui, R. Zhang, B. Ma, and J. Guo, "Mg deposition observed by in situ electrochemical Mg K-Edge X-ray absorption spectroscopy," Electrochemistry Communications, vol. 24, no. 1, pp. 43-46, 2012.

[116] S. Komaba, N. Yabuuchi, T. Nakayama, A. Ogata, T. Ishikawa, and I. Nakai, "Study on the reversible electrode reaction of $\mathrm{Na}_{1-x} \mathrm{Ni}_{0.5} \mathrm{Mn}_{0.5} \mathrm{O}_{2}$ for a rechargeable sodium-ion battery," Inorganic Chemistry, vol. 51, no. 11, pp. 6211-6220, 2012.

[117] J. J. Ding, Y. N. Zhou, Q. Sun, X. Q. Yu, X. Q. Yang, and Z. W. Fu, "Electrochemical properties of P2-Phase $\mathrm{Na}_{0.74} \mathrm{CoO}_{2}$ compounds as cathode material for rechargeable sodium-ion batteries," Electrochimica Acta, vol. 87, pp. 388-393, 2013.

[118] R. Dominko, I. Arčon, A. Kodre, D. Hanžel, and M. Gaberšček, "In-situ XAS study on $\mathrm{Li} 2 \mathrm{MnSiO} 4$ and $\mathrm{Li} 2 \mathrm{FeSiO} 4$ cathode materials," Journal of Power Sources, vol. 189, no. 1, pp. 51-58, 2009.

[119] J. Cabana, N. Dupré, F. Gillot, A. V. Chadwick, C. P. Grey, and M. R. Palacín, "Synthesis, short-range structure, and electrochemical properties of new phases in the Li-Mn-N-0 system," Inorganic Chemistry, vol. 48, no. 12, pp. 5141-5153, 2009.

[120] J. Gao, M. A. Lowe, Y. Kiya, and H. D. Abruña, "Effects of liquid electrolytes on the charge-discharge performance of rechargeable lithium/sulfur batteries: electrochemical and insitu X-ray absorption spectroscopic studies," Journal of Physical Chemistry C, vol. 115, no. 50, pp. 25132-25137, 2011.

[121] M. Balasubramanian, H. S. Lee, X. Sun et al., "Formation of SEI on cycled lithium-ion battery cathodes soft X-ray absorption study," Electrochemical and Solid-State Letters, vol. 5, no. 1, pp. A22-A25, 2002.

[122] H. M. Hollmark, K. Maher, I. Saadoune, T. Gustafsson, K. Edström, and L. C. Duda, "Resonant inelastic X-ray scattering and X-ray absorption spectroscopy on the negative electrode material Li0.5Ni0.25TiOPO 4 in a Li-ion battery," Physical Chemistry Chemical Physics, vol. 13, no. 14, pp. 6544-6551, 2011.
[123] J. Bartoll, "The early use of Prussian Blue in paintings", in Proceedings of the 9th International Conference on NDT of Art, Jerusalem, Israel, May 2008.

[124] H. J. Buser, D. Schwarzenbach, W. Petter, and A. Ludi, "The crystal structure of Prussian Blue: $\mathrm{Fe} 4[\mathrm{Fe}(\mathrm{CN}) 6] 3 \cdot x \mathrm{H} 2 \mathrm{O}$," Inorganic Chemistry, vol. 16, no. 11, pp. 2704-2710, 1977.

[125] J. Rodríguez-Hernández, E. Reguera, E. Lima, J. Balmaseda, R. Martínez-García, and H. Yee-Madeira, "An atypical coordination in hexacyanometallates: structure and properties of hexagonal zinc phases," Journal of Physics and Chemistry of Solids, vol. 68, no. 9, pp. 1630-1642, 2007.

[126] C. W. Ng, J. Ding, and L. M. Gan, "Structure and magnetic properties of Zn-Fe cyanide," Journal of Physics D, vol. 34, no. 8, pp. 1188-1192, 2001.

[127] C. M. Kareis, S. H. Lapidus, J. H. Her, P. W. Stephens, and J. S. Miller, "Non-Prussian Blue structures and magnetic ordering of $\mathrm{Na}_{2} \mathrm{Mn}^{I I}\left[\mathrm{Mn}^{I I}(\mathrm{CN})_{6}\right]$ and $\mathrm{Na}_{2} \mathrm{Mn}^{I I}\left[\mathrm{Mn}^{I I}(\mathrm{CN})_{6}\right] \cdot 2 \mathrm{H}_{2} \mathrm{O}$," The Journal of the American Chemical Society, vol. 134, no. 4, pp. 2246-2254, 2012.

[128] O. Sato, "Optically switchable molecular solids: photoinduced spin-crossover, photochromism, and photoinduced magnetization," Accounts of Chemical Research, vol. 36, no. 9, pp. 692-700, 2003.

[129] H. Tokoro and S. Ohkoshi, "Novel magnetif functionalities of Prussian Blue analogs," Dalton Transaction, vol. 40, no. 26, pp. 6813-7048, 2011.

[130] G. N. Newton, M. Nihei, and H. Oshio, "Cyanide-bridged molecular squares-The building units of Prussian Blue," European Journal of Inorganic Chemistry, no. 20, pp. 3031-3042, 2011.

[131] A. S. Wills, "Magnetism," Annual Reports on the Progress of Chemistry A, vol. 101, pp. 472-488, 2005.

[132] O. Sato, "Photoinduced magnetization in molecular compounds," Journal of Photochemistry and Photobuology C, vol. 5, no. 3, pp. 203-223, 2004.

[133] M. Verdaguer and G. Girolami, "Magnetic Prussian Blue analogs," in Magnetism: Molecules to Materials, S. Miller and M. Drillon, Eds., Wiley-VCH, Weinheim, Germany, 2004.

[134] S. Ferlay, T. Mallah, R. Ouahès, P. Veillet, and M. Verdaguer, "A room-temperature organometallic magnet based on Prussian Blue," Nature, vol. 378, no. 6558, pp. 701-703, 1995.

[135] N. R. De Tacconi, K. Rajeshwar, and R. O. Lezna, "Metal hexacyanoferrates: electrosynthesis, in situ characterization, and applications," Chemistry of Materials, vol. 15, no. 16, pp. 30463062, 2003.

[136] A. A. Karyak, "Prussian Blue and its analogues: electrochemistry and analytical applications," Electroanalysis, vol. 13, no. 10, pp. 813-819, 2001.

[137] W. Chen, S. Cai, Q. Q. Ren, W. Wen, and Y.-D. Zhao, "Recent advances in electrochemical sensing for hydrogen peroxide: a review," Analyst, vol. 137, no. 1, pp. 49-58, 2012.

[138] L. Guadagnini, D. Tonelli, and M. Giorgetti, "Improved copper hexacyanoferrate electrode for hydrogen peroxide detection," Electrochimica Acta, vol. 55, no. 17, pp. 5036-5039, 2010.

[139] J. Yang, H. Wang, L. Lu, W. Shi, and H. Zhang, "Large-scale synthesis of Berlin Green $\mathrm{Fe}\left[\mathrm{Fe}(\mathrm{CN})_{6}\right]$ microcubic crystals," Crystal Growth \& Design, vol. 6, no. 11, pp. 2438-2440, 2006.

[140] J. M. Domínguez-Vera and E. Colacio, "Nanoparticles of Prussian Blue ferritin: a new route for obtaining nanomaterials," Inorganic Chemistry, vol. 42, no. 22, pp. 6983-6985, 2003.

[141] X. Wu, M. Cao, C. Hu, and X. He, "Sonochemical synthesis of Prussian Blue nanocubes from a single-source precursor," Crystal Growth and Design, vol. 6, no. 1, pp. 26-28, 2006. 
[142] M. Berrettoni, M. Giorgetti, S. Zamponi et al., "Synthesis and characterization of nanostructured cobalt hexacyanoferrate," Journal of Physical Chemistry C, vol. 114, no. 14, pp. 6401-6407, 2010.

[143] A. Zanotto, R. Matassa, M. L. Saladino et al., "Cobalt hexacyanoferrate-poly(methyl methacrylate) composite: synthesis and characterization," Materials Chemistry and Physics, vol. 120, no. 1, pp. 118-122, 2010.

[144] M. Berrettoni, M. Giorgetti, J. A. Cox, D. Ranganathan, P. Conti, and S. Zamponi, "Electrochemical synthesis of nano-cobalt hexacyanoferrate at a sol-gel-coated electrode templated with $\beta$-cyclodextrin," Journal of Solid State Electrochemistry, vol. 16, no. 9, pp. 2861-2866, 2012.

[145] K. Hayakawa, K. Hatada, P. D’Angelo, S. Della Longa, C. R. Natoli, and M. Benfatto, "Full quantitative multiple-scattering analysis of X-ray absorption spectra: application to potassium hexacyanoferrat(II) and -(III) complexes," Journal of the American Chemical Society, vol. 126, no. 47, pp. 15618-15623, 2004.

[146] R. K. Hocking, E. C. Wasinger, F. M. F. de Groot, K. O. Hodgson, B. Hedman, and E. I. Solomon, "Fe L-edge XAS studies of $\mathrm{K}_{4}\left[\mathrm{Fe}(\mathrm{CN})_{6}\right]$ and $\mathrm{K}_{3}\left[\mathrm{Fe}(\mathrm{CN})_{6}\right]$ : a direct probe of back-bonding," Journal of the American Chemical Society, vol. 128, no. 32, pp. 10442-10451, 2006.

[147] N. Kosugi, T. Yokohama, and H. Kuroda, "Polarization dependence of XANES of square-planar $\mathrm{Ni}(\mathrm{CN}) 42$ - ion. A comparison with octahedral $\mathrm{Fe}(\mathrm{CN})_{6}^{4-}$ and $\mathrm{Fe}(\mathrm{CN})_{6}^{3-}$ ions," Chemical Physics, vol. 104, pp. 449-453, 1986.

[148] A. Kuzmin and P. Parent, "Focusing and superfocusing effects in X-ray absorption fine structure at the iron K edge in FeF3," Journal of Physics Condensed Matter, vol. 6, no. 23, pp. 43954404, 1994.

[149] M. Giorgetti, M. Berrettoni, A. Filipponi, P. J. Kulesza, and R. Marassi, "Evidence of four-body contributions in the EXAFS spectrum of $\mathrm{Na} 2 \mathrm{Co}[\mathrm{Fe}(\mathrm{CN}) 6]$," Chemical Physics Letters, vol. 275, no. 1-2, pp. 108-112, 1997.

[150] M. Giorgetti and M. Berrettoni, "Structure of Fe/Co/Ni hexacyanoferrate as probed by multiple edge X-ray absorption spectroscopy," Inorganic Chemistry, vol. 47, no. 13, pp. 60016008, 2008.

[151] P. A. Lee and J. B. Pendry, "Theory of the extended x-ray absorption fine structure," Physical Review B, vol. 11, no. 8, pp. 2795-2811, 1975.

[152] M. Benfatto, C. R. Natoli, A. Bianconi et al., "Multiple-scattering regime and higher-order correlations in $\mathrm{x}$-ray-absorption spectra of liquid solutions," Physical Review B, vol. 34, no. 8, pp. 5774-5781, 1986.

[153] C. Brouder, M. F. Ruiz Lopez, R. F. Pettifer, M. Benfatto, and C. R. Natoli, "Systematic approach to the calculation of the polarization-dependent (and polarization-averaged) general term of the curved-wave multiple-scattering series in the x-rayabsorption cross section," Physical Review B, vol. 39, no. 3, pp. 1488-1500, 1989.

[154] A. Di Cicco, "Multiple-edge EXAFS refinement: short-range structure in liquid and crystalline Sn," Physical Review B, vol. 53, no. 10, pp. 6174-6185, 1996.

[155] H. H. Zhang, A. Filipponi, A. Di Cicco et al., "Multipleedge XAS studies of cyanide-bridged iron-copper molecular assemblies relevant to cyanide-inhibited heme-copper oxidases using four-body multiple-scattering analysis," Journal of the American Chemical Society, vol. 119, no. 10, pp. 2470-2478, 1997.
[156] H. H. Zhang, A. Filipponi, A. D. Cicco et al., "Multiple-edge XAS studies of synthetic iron-copper bridged molecular assemblies relevant to cytochrome c oxidase. Structure determination using multiple-scattering analysis with statistical evaluation of errors," Inorganic Chemistry, vol. 35, no. 17, pp. 4819-4828, 1996.

[157] T. Yokoyama, T. Ohta, O. Sato, and K. Hashimoto, "Characterization of magnetic CoFe cyanides by $\mathrm{x}$-ray-absorption finestructure spectroscopy," Physical Review B, vol. 58, no. 13, pp. 8257-8266, 1998.

[158] T. Yokoyama, M. Kiguchi, T. Ohta, O. Sato, Y. Einaga, and K. Hashimoto, "Local structure of a trapped photoexcited state of a Fe-Co cyanide studied by x-ray-absorption fine-structure spectroscopy," Physical Review B, vol. 60, no. 13, pp. 9340-9346, 1999.

[159] A. Bleuzen, C. Lomenech, V. Escax et al., "Photoinduced ferrimagnetic systems in Prussian Blue analogues $\mathrm{C}(\mathrm{x})(\mathrm{I}) \mathrm{Co} 4$ $[\mathrm{Fe}(\mathrm{Cn}) 6](\mathrm{y})(\mathrm{C}(\mathrm{i})=$ alkali cation $) .1$. Conditions to observe the phenomenon," Journal of the American Chemical Society, vol. 122, no. 28, pp. 6648-6652, 2000.

[160] C. Cartier Dit Moulin, F. Villain, A. Bleuzen et al., "Photoinduced ferrimagnetic systems in Prussian Blue analogues $\mathrm{C}(\mathrm{I})(\mathrm{x}) \mathrm{Co} 4[\mathrm{Fe}(\mathrm{CN}) 6](\mathrm{y})(\mathrm{C}(\mathrm{I})=$ alkali cation $) .2$. X-ray absorption spectroscopy of the metastable state," Journal of the American Chemical Society, vol. 122, no. 28, pp. 6653-6658, 2000.

[161] V. Escax, A. Bleuzen, C. Cartier dit Moulin et al., "Photoinduced ferrimagnetic systems in Prussian Blue analogues CIxCo4 [Fe(CN)6]y (CI = Alkali Cation). 3. Control of the photo- and thermally induced electron transfer by the $[\mathrm{Fe}(\mathrm{CN}) 6]$ vacancies in cesium derivatives," Journal of the American Chemical Society, vol. 123, no. 50, pp. 12536-12543, 2001.

[162] M. Giorgetti, S. D. Longa, and M. Benfatto, "EXAFS and XANES simulations of Fe/Co hexacyanoferrate spectra by GNXAS and MXAN," Journal of Physics, vol. 190, Article ID 012145, 2009.

[163] T. Yokoyama, H. Tokoro, S. I. Ohkoshi, K. Hashimoto, K. Okamoto, and T. Ohta, "Photoinduced phase transition of $\mathrm{RbMnFe}(\mathrm{CN}) 6$ studied by $\mathrm{x}$-ray-absorption fine structure spectroscopy," Physical Review B, vol. 66, no. 18, Article ID 184111, pp. 1841111-18411110, 2002.

[164] T. Yokoyama, K. Okamoto, T. Otha, S. Ohkoshi, and K. Hashimoto, "Local structure and electrocin state of a photomagnetic material of CoW cyanide studied by X-ray absorption fine structure spectroscopy," Physical Review B, vol. 65, Article ID 064438, 2002.

[165] X. D. Ma, T. Yokoyama, T. Hozumi, K. Hashimoto, and S. I. Ohkoshi, "Electronic states and local structures of the photomagnetic $\mathrm{Cu}-\mathrm{Mo}$ cyanides $\mathrm{Cu} 2 \mathrm{Mo}(\mathrm{CN}) 88 \mathrm{H} 2 \mathrm{O}$ and $\mathrm{Cs} 0.5 \mathrm{Cu}$. $75 \mathrm{Mo}(\mathrm{CN}) 81.5 \mathrm{H} 2 \mathrm{O}$ studied by $\mathrm{x}$-ray absorption fine structure spectroscopy," Physical Review B, vol. 72, no. 9, pp. 1-6, 2005.

[166] E. I. Solomon, B. Hedman, K. O. Hodgson, A. Dey, and R. K. Szilagyi, "Ligand K-edge X-ray absorption spectroscopy: covalency of ligand-metal bonds," Coordination Chemistry Reviews, vol. 249, no. 1-2, pp. 97-129, 2005.

[167] M. A. Arrio, P. Sainctavit, C. Cartier Dit Moulin et al., "Characterization of chemical bonds in bimetallic cyanides using X-ray absorption spectroscopy at L2,3 edges," Journal of the American Chemical Society, vol. 118, no. 27, pp. 6422-6427, 1996.

[168] V. Escax, G. Champion, M. A. Arrio, M. Zacchigna, C. C. D. Moulin, and A. Bleuzen, "The Co ligand field: a key parameter in photomagnetic CoFe Prussian Blue derivatives," Angewandte Chemie, vol. 44, no. 30, pp. 4798-4801, 2005.

[169] A. Bleuzen, V. Escax, A. Ferrier et al., "Thermally induced electron transfer in a CsCoFe Prussian Blue derivative: the 
specific role of the alkali-metal ion," Angewandte Chemie, vol. 43, no. 28, pp. 3728-3731, 2004.

[170] S. Bonhommeau, N. Pontius, S. Cobo et al., "Metal-to-ligand and ligand-to-metal charge transfer in thin films of Prussian Blue analogues investigated by X-ray absorption spectroscopy," Physical Chemistry Chemical Physics, vol. 10, no. 38, pp. 58825889, 2008.

[171] P. J. Kulesza, M. A. Malik, M. Berrettoni et al., "Electrochemical charging, counter-cation accomodation, and spectrochemical identity of microcrystalline solid cobalt hexacyanoferrate," Journal of Physical Chemistry B, vol. 102, no. 11, pp. 1870-1876, 1998.

[172] P. J. Kulesza, M. A. Malik, J. Skorek et al., "Hybrid metal cyanometallates electrochemical charging and spectrochemical identity of heteronuclear nickel/cobalt hexacyanoferrate," Journal of the Electrochemical Society, vol. 146, no. 10, pp. 3757-3761, 1999.

[173] K. H. Hallmeier, S. Sauter, and R. Szargan, "XANES and EXAFS investigations of bonding and structure of $\mathrm{Ni}$ and Co derivatives from Prussian Blue coordination compounds," Inorganic Chemistry Communications, vol. 4, no. 3, pp. 153-156, 2001.

[174] W. A. Steen, S. W. Han, Q. Yu et al., "Structure of cathodically deposited nickel hexacyanoferrate thin films using XRD and EXAFS," Langmuir, vol. 18, no. 20, pp. 7714-7721, 2002.

[175] S. Zamponi, M. Giorgetti, M. Berrettoni, P. J. Kulesza, J. A. Cox, and A. M. Kijak, "Cobalt hexacyanoferrate in PAMAMdoped silica matrix: 1 . Solid state electrochemistry and thermochromism," Electrochimica Acta, vol. 51, no. 1, pp. 118-124, 2005.

[176] M. Giorgetti, M. Berrettoni, S. Zamponi, P. J. Kulesza, and J. A. Cox, "Cobalt hexacyanoferrate in PAMAM doped silica matrix. 2. Structural and electronic characterization," Electrochimica Acta, vol. 51, no. 3, pp. 511-516, 2005.

[177] A. R. Hillman, M. A. Skopek, and S. J. Gurman, "EXAFS structural studies of electrodeposited Co and $\mathrm{Ni}$ hexacyanoferrate films," Journal of Solid State Electrochemistry, vol. 14, no. 11, pp. 1997-2010, 2010.

[178] M. Giorgetti, L. Guadagnini, D. Tonelli, M. Minicucci, and G. Aquilanti, "Structural characterization of electrodeposited copper hexacyanoferrate films by using a spectroscopic multitechnique approach," Physical Chemistry Chemical Physics, vol. 14, no. 16, pp. 5527-5537, 2012.

[179] M. Giorgetti, G. Aquilanti, and M. Minicucci, "Structural study of the $\mathrm{Cu}^{2+}$-loaded copper hexacyanoferrate electrode deposited on ITO substrate," Journal of Physics, vol. 430, Article ID 012049, 2013.

[180] A. Bleuzen, J. D. Cafun, A. Bachschmidt et al., "CoFe Prussian Blue analogues under variable pressure. Evidence of departure from cubic symmetry: X-ray diffraction and absorption study," Journal of Physical Chemistry C, vol. 112, no. 45, pp. 17709-17715, 2008.

[181] K. Ishiji, T. Matsuda, H. Tokoro, T. Iwazumi, K. Hashimoto, and S. I. Ohkoshi, "Observation of phase transition of cesium manganese hexacyanoferrates by X-ray absorption spectroscopy," Journal of Physics and Chemistry of Solids, vol. 68, no. 11, pp. 2158-2161, 2007.

[182] I. Jarrige, Y. Q. Cai, H. Ishii, N. Hiraoka, and A. Bleuzen, “Thermally activated charge transfer in a Prussian Blue derivative probed by resonant inelastic x-ray scattering," Applied Physics Letters, vol. 93, no. 5, Article ID 054101, 2008.

[183] Y. Nanba, D. Asakura, M. Okubo et al., "Configurationinteraction full-multiplet calculation to analyze the electronic structure of a cyano-bridged coordination polymer electrode," Journal of Physical Chemistry C, vol. 116, no. 47, pp. 2489624901, 2012.

[184] Y. Nanba and K. Okada, "Theory of Fe and Mn 2p X-ray absorption for $\mathrm{RbMn}\left[\mathrm{Fe}(\mathrm{CN})_{6}\right]$," Journal of Electron Spectroscopy and Related Phenomena, vol. 185, no. 5-7, pp. 167-174, 2012.

[185] Y. Nanba and K. Okada, "Charge transfer effects on Fe 2p $\mathrm{X}$-ray photoemission of $\mathrm{RbMn}[\mathrm{Fe}(\mathrm{CN}) 6], \mathrm{K} 3 \mathrm{Fe}(\mathrm{CN}) 6$, and K4Fe(CN)6," Journal of the Physical Society of Japan, vol. 80, no. 7, Article ID 074710, 2011.

[186] M. Ware, "Prussian Blue: artists' pigment and chemists' sponge," Journal of Chemical Education, vol. 85, no. 5, pp. 612-620, 2008.

[187] L. Samain, G. Silversmit, J. Sanyova et al., "Fading of modern Prussian Blue pigments in linseed oil medium," Journal of Analytical Atomic Spectrometry, vol. 26, no. 5, pp. 930-941, 2011.

[188] G. Dupouy, I. Bonhoure, S. D. Conradson et al., "Local structure in americium and californium hexacyanoferrates-comparison with their lanthanide analogues," European Journal of Inorganic Chemistry, no. 10, pp. 1560-1569, 2011.

[189] I. Bonhoure, C. D. Auwer, C. C. Dit Moulin, P. Moisy, J. C. Berthet, and C. Madic, "Molecular and electronic structure of $\mathrm{An}(\mathrm{IV}) \mathrm{Fe}(\mathrm{II})(\mathrm{Cn}) 6 \cdot x \mathrm{H} 2 \mathrm{O}(\mathrm{An}=\mathrm{Th}, \mathrm{U}, \mathrm{Np})$ compounds: an Xray absorption spectroscopy investigation," Canadian Journal of Chemistry, vol. 78, no. 10, pp. 1305-1317, 2000.

[190] P. Glatzel, L. Jacquamet, U. Bergmann, F. M. F. De Groot, and S. P. Cramer, "Site-selective EXAFS in mixed-valence compounds using high-resolution fluorescence detection: a study of iron in Prussian Blue," Inorganic Chemistry, vol. 41, no. 12, pp. 3121-3127, 2002.

[191] X. Duan and D. G. Evans, Eds., Layered Double Hydroxides, Structure and Bonding, Springer, Berlin, Germany, 2006.

[192] A. de Roy, C. Forano, K. El Malki, and J. P. Besse, "Synthesis of microporous materials," in Expanded Clays and other Microporous Stystems, M. L. Occelli and H. E. Robson, Eds., vol. 2, pp. 108-169, Van Nostrand Reinhold, New York, NY, USA, 1992.

[193] F. Cavani, F. Trifirò, and A. Vaccari, "Hydrotalcite-type anionic clays: preparation, properties and applications," Catalysis Today, vol. 11, no. 2, pp. 173-301, 1991.

[194] V. Rives and M. A. Ulibarri, "Layered double hydroxides (LDH) intercalated with metal coordination compounds and oxometalates," Coordination Chemistry Reviews, vol. 181, no. 1, pp. 61-120, 1999.

[195] S. K. Jana, Y. Kubota, and T. Tatsumi, "Cobalt-substituted polyoxometalate pillared hydrotalcite: synthesis and catalysis in liquid-phase oxidation of cyclohexanol with molecular oxygen," Journal of Catalysis, vol. 255, no. 1, pp. 40-47, 2008.

[196] Z. Tong, T. Shichi, and K. Takagi, "Oxidation catalysis of a manganese(III)porphyrin intercalated in layered double hydroxide clays," Materials Letters, vol. 57, no. 15, pp. 2258-2261, 2003.

[197] E. M. Moujahid, J. Inacio, J. P. Besse, and F. Leroux, "Adsorption of styrene sulfonate versus polystyrene sulfonate on layered double hydroxides," Microporous and Mesoporous Materials, vol. 57, no. 1, pp. 37-46, 2003.

[198] D. Tonelli, E. Scavetta, and M. Giorgetti, "Layered double hydroxide modified electrodes: electroanalytical applications," Analytical and Bioanalytical Chemistry, vol. 405, no. 2-3, pp. 603-614, 2013.

[199] C. Mousty, C. Forano, S. Fleutot, and J. C. Dupin, "Electrochemical study of anionic ferrocene derivatives intercalated in layered double hydroxides: application to glucose amperometric biosensors," Electroanalysis, vol. 21, no. 3-5, pp. 399-408, 2009. 
[200] W. Shi, M. Wei, D. G. Evans, and X. Duan, "Tunable photoluminescence properties of fluorescein in a layered double hydroxide matrix and its application in sensors," Journal of Materials Chemistry, vol. 20, no. 19, pp. 3901-3909, 2010.

[201] X. Guo, F. Zhang, D. G. Evans, and X. Duan, "Layered double hydroxide films: synthesis, properties and applications," Chemical Communications, vol. 46, no. 29, pp. 5197-5210, 2010.

[202] Y. Guo, D. Li, C. Hu et al., "Photocatalytic degradation of aqueous organocholorine pesticide on the layered double hydroxide pillared by Paratungstate $\mathrm{A}$ ion, $\mathrm{Mg}_{12} \mathrm{Al}_{6}(\mathrm{OH})_{36}$ $\left(\mathrm{W}_{7} \mathrm{O}_{42}\right) \cdot 4 \mathrm{H}_{2} \mathrm{O}$," Applied Catalysis B, vol. 30, no. 3-4, pp. 337349, 2001.

[203] V. Rives, F. M. Labajos, M. A. Ulibarri, and P. Malet, "A new hydrotalcite-like compound containing V3+ ions in the layers," Inorganic Chemistry, vol. 32, no. 23, pp. 5000-5001, 1993.

[204] W. Li, K. J. T. Livi, W. Xu et al., "Formation of crystalline Zn-Al layered double hydroxide precipitates on $\gamma$-alumina: the role of mineral dissolution," Environmental Science \& Technology, vol. 46, no. 21, pp. 11670-11677, 2012.

[205] K. J. T. Livi, G. S. Senesi, A. C. Scheinost, and D. L. Sparks, "Microscopic examination of nanosized mixed Ni-Al hydroxide surface precipitates on pyrophyllite," Environmental Science and Technology, vol. 43, no. 5, pp. 1299-1304, 2009.

[206] C. Priadi, P. Le Pape, G. Morin et al., "X-ray absorption fine structure evidence for amorphous zinc sulfide as a major zinc species in suspended matter from the seine river downstream of Paris, Ile-De-France, france," Environmental Science and Technology, vol. 46, no. 7, pp. 3712-3720, 2012.

[207] O. Jacquat, A. Voegelin, and R. Kretzschmar, "Soil properties controlling $\mathrm{Zn}$ speciation and fractionation in contaminated soils," Geochimica et Cosmochimica Acta, vol. 73, no. 18, pp. 5256-5272, 2009.

[208] O. Jacquat, A. Voegelin, A. Villard, M. A. Marcus, and R. Kretzschmar, "Formation of Zn-rich phyllosilicate, Zn-layered double hydroxide and hydrozincite in contaminated calcareous soils," Geochimica et Cosmochimica Acta, vol. 72, no. 20, pp. 5037-5054, 2008.

[209] M. Nachtegaal and D. L. Sparks, "Nickel sequestration in a kaolinite-humic acid complex," Environmental Science and Technology, vol. 37, no. 3, pp. 529-534, 2003.

[210] Y. T. Liu, M. K. Wang, T. Y. Chen, P. N. Chiang, P. M. Huang, and J. F. Lee, "Arsenale sorption on lithium/aluminum layered double hydroxide intercalated by chloride and on gibbsite: sorption isotherms, envelopes, and spectroscopic studies," Environmental Science and Technology, vol. 40, no. 24, pp. 77847789, 2006.

[211] N. U. Yamaguchi, A. C. Scheinost, and D. L. Sparks, "Influence of gibbsite surface area and citrate on Ni sorption mechanisms at pH 7.5," Clays and Clay Minerals, vol. 50, no. 6, pp. 784-790, 2002.

[212] E. J. Elzinga and D. L. Sparks, "Reaction condition effects on nickel sorption mechanisms in illite-water suspensions," Soil Science Society of America Journal, vol. 65, no. 1, pp. 94-101, 2001.

[213] J. Hu, X. Tan, X. Ren, and X. Wang X, "Effect of humic acid on nickel(ii) sorption to Ca-montmorillonite by batch and EXAFS techniques study," Dalton Transactions, vol. 41, no. 35, pp. 10803-10810, 2012.

[214] M. Nachtegaal and D. L. Sparks, "Effect of iron oxide coatings on zinc sorption mechanisms at the clay-mineral/water interface," Journal of Colloid and Interface Science, vol. 276, no. 1, pp. 13-23, 2004.
[215] D. R. Roberts, R. G. Ford, and D. L. Sparks, "Kinetics and mechanisms of $\mathrm{Zn}$ complexation on metal oxides using EXAFS spectroscopy," Journal of Colloid and Interface Science, vol. 263, no. 2, pp. 364-376, 2003.

[216] L. Aimoz, C. Taviot-Guého, S. V. Churakov et al., "Anion and cation order in iodide-bearing $\mathrm{Mg} / \mathrm{Zn}$-Al layered double hydroxides," The Journal of Physical Chemistry C, vol. 116, no. 9, pp. 5460-5475, 2012.

[217] B. Monteiro, S. Gago, F. A. Almeida Paz, R. Bilsborrow, I. S. Gonçalves, and M. Pillinger, "Investigation of layered double hydroxides intercalated by oxomolybdenum catecholate complexes," Inorganic Chemistry, vol. 47, no. 19, pp. 8674-8686, 2008.

[218] S. Gago, M. Pillinger, R. A. Sá Ferreira, L. D. Carlos, T. M. Santos, and L. S. Gonçalves, "Immobilization of Lanthanide Ions in a Pillared Layered Double Hydroxide," Chemistry of Materials, vol. 17, no. 23, pp. 5803-5809, 2005.

[219] M. Doeuff, T. Kwon, and T. J. Pinnavaia, "Layered double hydroxides pillared by polyoxometalate anions: EXAFS studies and chemical synthesis," Synthetic Metals, vol. 34, no. 1-3, pp. 609-615, 1989 .

[220] E. M. Moujahid, J. P. Besse, and F. Leroux, "Poly(styrene sulfonate) layered double hydroxide nanocomposites. Stability and subsequent structural transformation with changes in temperature," Journal of Materials Chemistry, vol. 13, no. 2, pp. 258-264, 2003.

[221] C. Vaysse, L. Guerlou-Demourgues, A. Demourgues, and C. Delmas, "Thermal behavior of oxometalate (Mo, W)-intercalated layered double hydroxides: study of the grafting phenomenon," Journal of Solid State Chemistry, vol. 167, no. 1, pp. 59-72, 2002.

[222] L. Bigey, C. Depege, A. de Roy, and J. P. Besse, "EXAFS and XANES study of layered double hydroxides," in Proceedings of the 1996 9th International Conference on X-Ray Absorption Fine Structure. Part 2, pp. C2-950, August 1996.

[223] F. Malherbe, L. Bigey, C. Forano, A. De Roy, and J. P. Besse, "Structural aspects and thermal properties of takovite-like layered double hydroxides pillared with chromium oxo-anions," Journal of the Chemical Society, no. 21, pp. 3831-3839, 1999.

[224] C. Taviot-Guého, F. Leroux, C. Payen, and J. P. Besse, "Cationic ordering and second-staging structures in copper-chromium and zinc-chromium layered double hydroxides," Applied Clay Science, vol. 28, no. 1-4, pp. 111-120, 2005.

[225] H. Roussel, V. Briois, E. Elkaim, A. De Roy, J. P. Besse, and J. P. Jolivet, "Study of the formation of the layered double hydroxide [Zn-Cr-Cl]," Chemistry of Materials, vol. 13, no. 2, pp. 329-337, 2001.

[226] S. Ariasa, J. G. Eona, R. A. S. San Gila, Y. E. Liceaa, L. A. Palacio, and A. C. Faro Jr., "Synthesis and characterization of terephthalate-intercalated NiAl layered double hydroxides with high Al content," Dalton Transaction, vol. 42, no. 6, pp. 20842093, 2013.

[227] D. A. Boga, R. Oord, A. M. Beale, Y. Chung, P. C. A. Bruijnincx, and B. M. Weckhuysen, "Highly selective Bimetallic Pt-Cu/ $\mathrm{Mg}(\mathrm{Al}) \mathrm{O}$ catalysts for the aqueous-phase reforming of glycerol," Chem CatChem, vol. 5, no. 2, pp. 529-537, 2013.

[228] Y. Zhao, P. Chen, B. Zhang et al., "Highly dispersed TiO 6 units in a layered double hydroxide for water splitting," Chemistry, vol. 18, no. 38, pp. 11949-11958, 2012.

[229] I. J. Shannon, T. Maschmeyer, G. Sankar et al., "A new cell for the collection of combined EXAFS/XRD data in situ during 
solid/liquid catalytic reactions," Catalysis Letters, vol. 44, no. 1-2, pp. 23-27, 1997.

[230] Y. Lu, M. Wei, L. Yang, and C. Li, "Synthesis of layered cathode material $\mathrm{Li}[\mathrm{CoxMnl-x}]_{2}$ from layered double hydroxides precursors," Journal of Solid State Chemistry, vol. 180, no. 5, pp. 1775-1782, 2007.

[231] I. Carpani, M. Giorgetti, M. Berrettoni, P. Luigi Buldini, M. Gazzano, and D. Tonelli, "A new approach for the synthesis of K+free nickel hexacyanoferrate," Journal of Solid State Chemistry, vol. 179, no. 12, pp. 3981-3988, 2006.

[232] A. Corma, F. Rey, J. M. Thomas et al., "On the atomic environment and the mode of action of the catalytic centre in an intercalated oxo-molybdenum complex $\left[\mathrm{MoO}_{2} \mathrm{O}_{2} \mathrm{CC}(\mathrm{S}) \mathrm{Ph}_{22}\right]_{2}$ - for oxygen-transfer reactions," Chemical Communications, no. 14, pp. 1613-1614, 1996.

[233] S. Bonnet, L. Bigey, C. Forano et al., "Intercalation of porphyrin in Zn-Al layered double hydroxides," in Synthesis of Microporous Materials: Zeolytes, Clays and Nanostructures, M. L. Occelli and H. Kessler, Eds., pp. 627-640, Marcel Dekker, Ney York, NY, USA, 1997.

[234] I. Carpani, M. Berrettoni, B. Ballarin, M. Giorgetti, E. Scavetta, and D. Tonelli, "Study on the intercalation of hexacyanoferrate(II) in a Ni, Al based hydrotalcite," Solid State Ionics, vol. 168, no. 1-2, pp. 167-175, 2004.

[235] I. Carpani, M. Berrettoni, M. Giorgetti, and D. Tonelli, "Intercalation of iron(III) hexacyano complex in a Ni,Al hydrotalcitelike compound," Journal of Physical Chemistry B, vol. 110, no. 14, pp. 7265-7269, 2006.

[236] C. Vaysse, L. Gueriou-Demourgues, A. Demourgues, F. Lazartigues, D. Fertier, and C. Delmas, "New (Ni, Co)-based layered double hydroxides with intercalated oxometalate (Mo, W) species, obtained by chimie douce reactions," Journal of Materials Chemistry, vol. 12, no. 4, pp. 1035-1043, 2002.

[237] C. Depège, L. Bigey, C. Forano, A. De Roy, and J. P. Besse, "Synthesis and characterization of new copper-chromium layered double hydroxides pillared with polyoxovanadates," Journal of Solid State Chemistry, vol. 126, no. 2, pp. 314-323, 1996.

[238] B. Ballarin, A. Mignani, E. Scavetta et al., "Novel synthetic route for supported gold nanoparticles Nial Layered Double Hydroxide, catalyst efficiency towards electro-oxydation of methanol," Langmuir, vol. 28, no. 42, pp. 15065-15074, 2012.

[239] G. Defontaine, L. J. Michot, I. Bihannic, J. Ghanbaja, and V. Briois, "Synthesis of NiGa layered double hydroxides. A combined extended $\mathrm{x}$-ray absorption fine structure, small-angle $\mathrm{x}$ ray scattering, and transmission electron microscopy study. 1. Hydrolysis in the pure Ni2+ system," Langmuir, vol. 19, no. 25, pp. 10588-10600, 2003.

[240] G. Defontaine, L. J. Michot, I. Bihannic, J. Ghanbaja, and V. Briois, "Synthesis of NiGa layered double hydroxides. A combined EXAFS, SAXS, and TEM study. 3. Synthesis at constant pH," Langmuir, vol. 20, no. 25, pp. 11213-11222, 2004.

[241] G. Defontaine, L. J. Michot, I. Bihannic, J. Ghanbaja, and V. Briois, "Synthesis of NiGa layered double hydroxides. A combined EXAFS, SAXS, and TEM study. 2. Hydrolysis of a Ni2+/Ga3+ solution," Langmuir, vol. 20, no. 22, pp. 9834-9843, 2004.

[242] S. Vial, V. Prevot, F. Leroux, and C. Forano, "Immobilization of urease in $\mathrm{ZnAl}$ Layered Double Hydroxides by soft chemistry routes," Microporous and Mesoporous Materials, vol. 107, no. 1-2, pp. 190-201, 2008.
[243] H. Funke, A. C. Scheinost, and M. Chukalina, "Wavelet analysis of extended x-ray absorption fine structure data," Physical Review B, vol. 71, no. 9, pp. 1-7, 2005.

[244] T. Enoki, M. Suzuki, and M. Endo, Graphite Intercalation Compounds and Applications, Oxford University Press, Oxford, UK, 2003.

[245] S. M. Heald and E. A. Stern, "Extended-x-ray-absorption-finestructure study of the Br2-graphite system," Physical Review B, vol. 17, no. 10, pp. 4069-4081, 1978.

[246] T. Roisnel, A. Tressaud, J. Grannec, H. Dexpert, and S. Flandrois, "EXAFS study of transition metal chlorides intercalated in graphite," Solid State Communications, vol. 73, no. 8, pp. 547$550,1990$.

[247] N. V. Bausk, S. B. Érenburg, N. F. Yudanov, and L. N. Mazalov, "Geometry and orientation of molecules in a graphite fluoride matrix," Journal of Structural Chemistry, vol. 37, no. 6, pp. 913919, 1996.

[248] N. V. Bausk, S. B. Érenburg, N. F. Yudanov, and L. N. Mazalov, "Determining the orientations of $\mathrm{BrF} 3$ and $\mathrm{FeBr} 3$ molecules in graphite fluoride matrices using the XANES and EXAFS polarization dependences," Journal of Structural Chemistry, vol. 36, no. 6, pp. 932-940, 1995.

[249] G. Faraci, S. La Rosa, A. R. Pennisi, S. Mobilio, and I. Pollini, "Islandlike in-plane structure and vibrational behavior of $\mathrm{NiCl} 2$ intercalated in graphite," Physical Review B, vol. 43, no. 3, pp. 1913-1918, 1991.

[250] J. Ehrich, P. Behrens, W. Metz, and W. Niemann, "X-ray absorption spectroscopy and X-ray diffraction of $\mathrm{AuCl}_{3}$-graphite," Synthetic Metals, vol. 34, no. 1-3, pp. 217-222, 1989.

[251] A. V. Dunaev, I. V. Arkhangelsky, Y. V. Zubavichus, and V. V. Avdeev, "Preparation, structure and reduction of graphite intercalation compounds with hexachloroplatinic acid," Carbon, vol. 46, no. 5, pp. 788-795, 2008.

[252] H. Yoshikawa, K. Fukuyama, Y. Nakahara et al., "X-ray absorption fine structure study on residue bromine in carbons with different degrees of graphitization," Carbon, vol. 41, no. 15, pp. 2931-2938, 2003.

[253] M. Shirai, K. Igeta, and M. Arai, "Insertion and aggregation behavior of PtCl4 between graphite layers," Studies in Surface Science and Catalysis, vol. 132, pp. 761-764, 2001.

[254] P. Thuéry, "Solid state structure of thorium(IV) complexes with common aminopolycarboxylate ligands," Inorganic Chemistry, vol. 50, no. 5, pp. 1898-1904, 2011.

[255] T. Yamamoto, T. Matsuyama, T. Tanaka, T. Funabiki, and S. Yoshida, "Silica-supported ytterbium oxide characterized by spectroscopic methods and acid-catalyzed reactions," Journal of Molecular Catalysis A, vol. 155, no. 1-2, pp. 43-58, 2000.

[256] S. J. Clarke, P. Adamson, S. J. C. Herkelrath et al., "Structures, physical properties, and chemistry of layered oxychalcogenides and oxypnictides," Inorganic Chemistry, vol. 47, no. 19, pp. 84738486, 2008.

[257] S. Ganorkar, K. R. Priolkar, P. R. Sarode, A. Banerjee, R. Rawat, and S. Emura, "Influence of local structure on magnetic properties of layered cobaltites $\operatorname{PrBaCo}(2) \mathrm{O}(5+\delta), \delta>0.5$," Journal of Physics Condensed Matter, vol. 24, no. 47, Article ID 476003, 2012.

[258] J. H. Choy, J. Y. Kim, and I. Chung, "Neutron diffraction and Xray absorption spectroscopic analyses for lithiated aurivilliustype layered perovskite oxide, $\mathrm{Li}_{2} \mathrm{Bi}_{4} \mathrm{Ti}_{3} \mathrm{O}_{12}$," Journal of Physical Chemistry B, vol. 105, no. 33, pp. 7908-7912, 2001. 
[259] S. Riegg, A. Reller, and S. G. Ebbinghaus, "Single crystalline and rare earth substituted $\mathrm{La}_{2} \mathrm{RuO}_{5}$ investigated by X-ray diffraction and EXAFS spectroscopy," Journal of Solid State Chemistry, vol. 188, pp. 17-25, 2012.

[260] S. J. Gurman, J. C. Amiss, M. Khaled, N. L. Saini, and K. B. Garg, "X-ray absorption study of the (Y1-xPrx)Ba2Cu3O7- $\delta$ system," Journal of Physics Condensed Matter, vol. 11, no. 7, pp. 1847-1859, 1999.

[261] H. Oyanagi, N. L. Saini, and A. Bianconi, "Local lattice distortions in $\mathrm{YBa} 2 \mathrm{Cu} 3 \mathrm{Oy}$ probed by XAS: critical fluctuation, pseudogap opening and stripe ordering," International Journal of Modern Physics B, vol. 14, no. 29-31, pp. 3623-3631, 2000.

[262] P. Ghigna, S. Pin, G. Spinolo et al., “ $\mu$-XANES mapping of buried interfaces: pushing microbeam techniques to the nanoscale," Physical Chemistry Chemical Physics, vol. 12, no. 21, pp. 5547-5550, 2010.

[263] S. Pascarelli and O. Mathon, "Advances in high brilliance energy dispersive X-ray absorption spectroscopy," Physical Chemistry Chemical Physics, vol. 12, no. 21, pp. 5535-5546, 2010.

[264] M. Giorgetti, S. Tonelli, A. Zanelli, G. Aquilanti, M. Pellei, and C. Santini, "Synchrotron radiation X-ray absorption spectroscopic studies in solution and electrochemistry of a nitroimidazole conjugated heteroscorpionate copper(II) complex," Polyhedron, vol. 48, no. 1, pp. 174-180, 2012.

[265] M. Pellei, G. Papini, S. Trasatti et al., "Nitroimidazole and glucosamine conjugated heteroscorpionate ligands and related copper(ii) complexes. Syntheses, biological activity and XAS studies," Dalton Transaction, vol. 40, no. 38, pp. 9877-9888, 2011.

[266] Y. Wen Hsiao, Y. Tao, J. E. Sholes, R. A. Scott, and U. Ryde, "EXAFS structure refinement supplemented by computational chemistry," Physical Review B, vol. 74, no. 21, Article ID 214101, 2006.

[267] P. D’Angelo, A. Zitolo, V. Migliorati, G. Mancini, I. Persson, and G. Chillemi, "Structural investigation of lanthanoid coordination: a combined XANES and molecular dynamics study," Inorganic Chemistry, vol. 48, no. 21, pp. 10239-10248, 2009.

[268] A. Witkowska, J. Rybicki, and A. Di Cicco, "Structure of partially reduced bismuth-silicate glasses: EXAFS and MD study," Journal of Alloys and Compounds, vol. 401, no. 1-2, pp. 135-144, 2005.

[269] O. M. Roscioni, N. Zonias, S. W. T. Price, A. E. Russell, T. Comaschi, and C. K. Skylaris, "Computational prediction of L3 EXAFS spectra of gold nanoparticles from classical molecular dynamics simulations," Physical Review B, vol. 83, no. 11, Article ID 115409, 2011. 

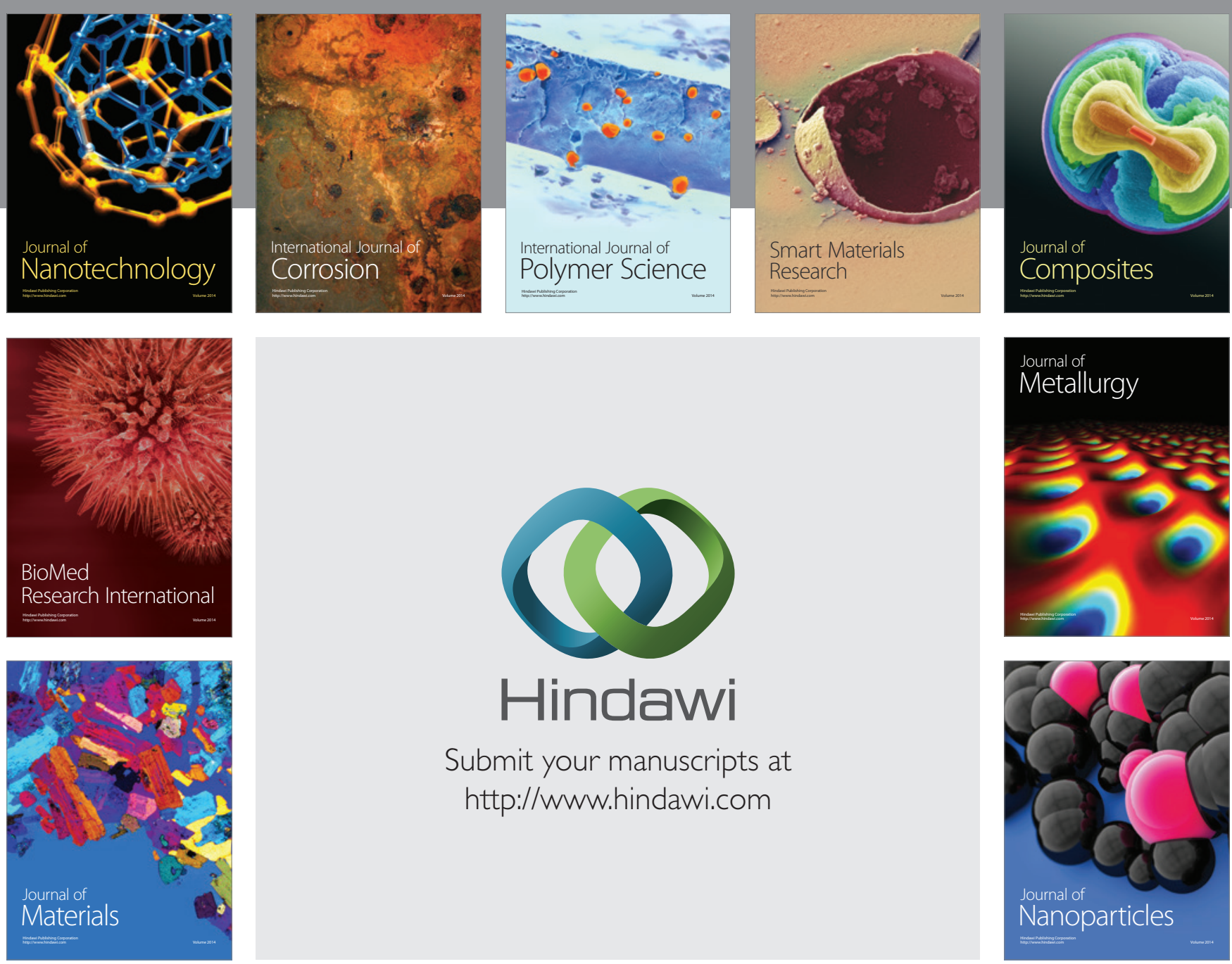

Submit your manuscripts at http://www.hindawi.com
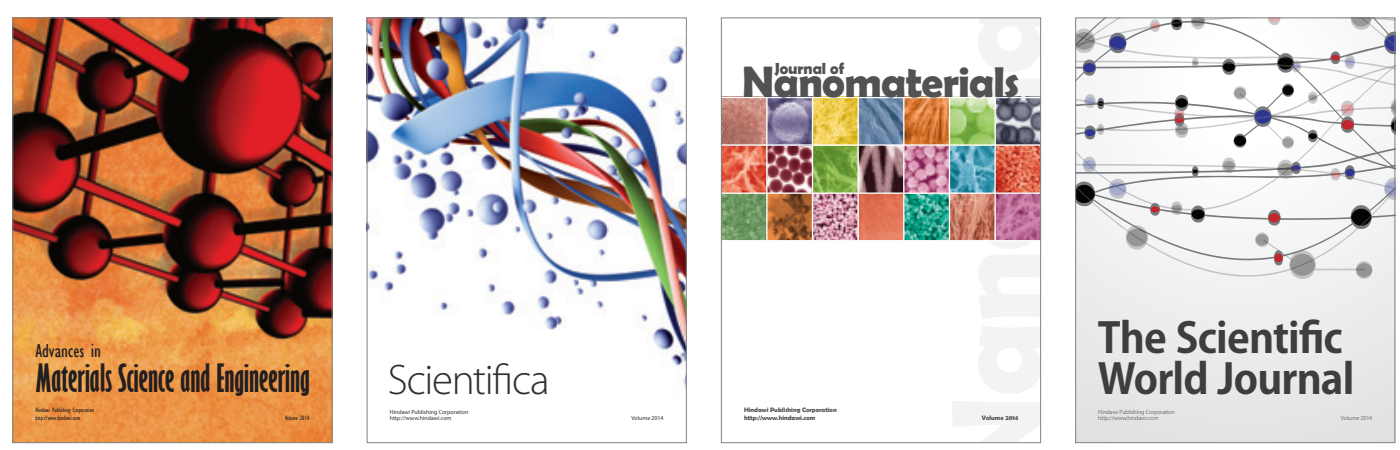

\section{The Scientific World Journal}
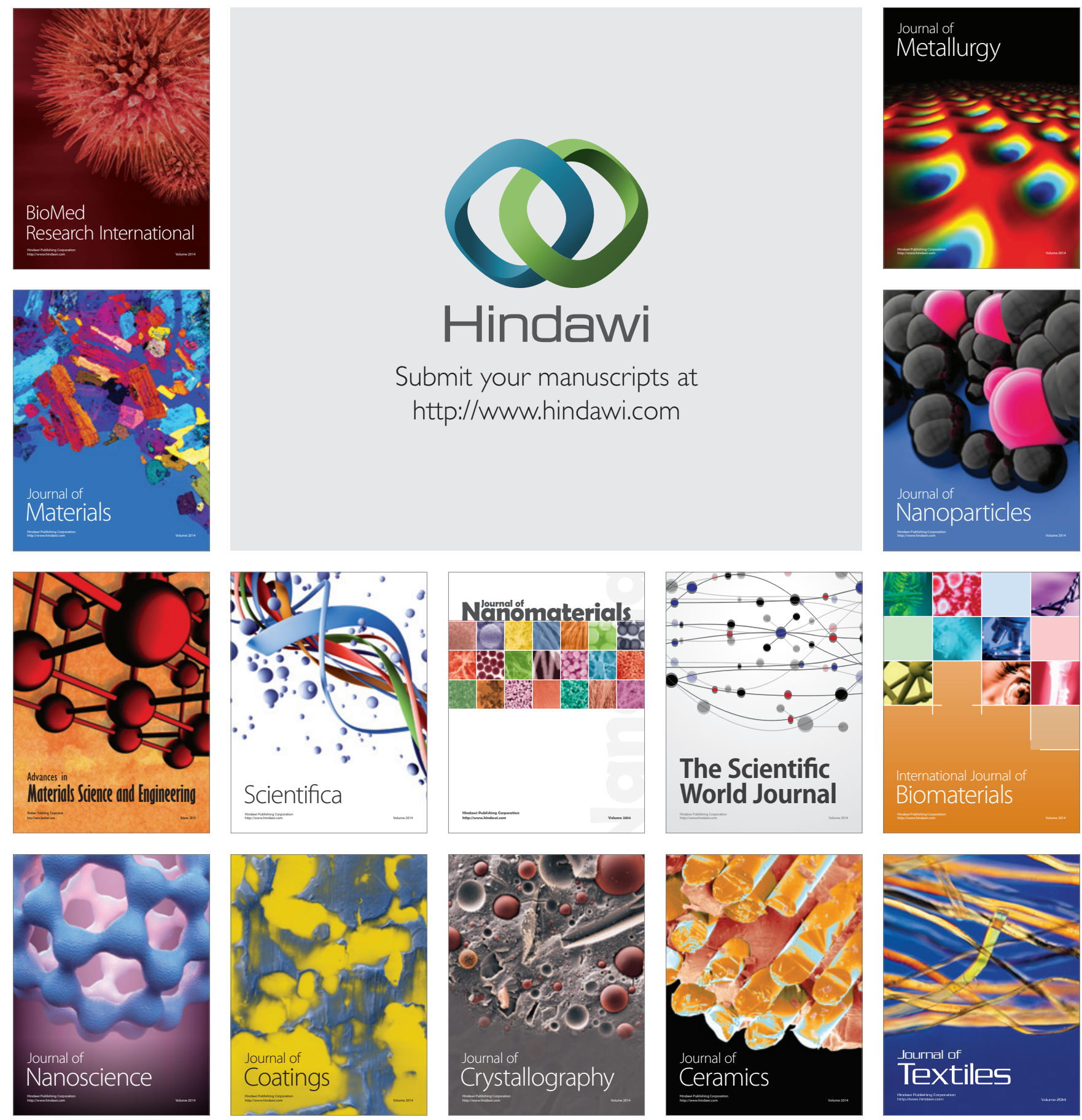